\title{
Optimization of novel single-step gelatin extraction method using RSM model for valorization of surimi industry by-products
}

\section{Khushboo}

Amity University Uttar Pradesh, Noida https://orcid.org/0000-0001-5768-7366

Nutan Kaushik ( $\nabla$ kaushikn2008@gmail.com)

Amity University Uttar Pradesh, Noida

Kristina Norne Widell

SINTEF Ocean, Norway

Rasa Slizyte

SINTEF Ocean, Norway

Asha Kumari

Amity University Uttar Pradesh, Noida https://orcid.org/0000-0002-2554-5627

\section{Research Article}

Keywords: Gelatin, Pink Perch, RSM, by-product utilization, Nemipterus japonicus, Rheological properties

Posted Date: January 14th, 2022

DOI: https://doi.org/10.21203/rs.3.rs-1261080/v1

License: (c) (i) This work is licensed under a Creative Commons Attribution 4.0 International License. Read Full License 


\section{Optimization of novel single step gelatin extraction method using RSM model for}

\section{2 valorisation of surimi industry by-products}

3 Khushboo $^{1,2}$, Nutan Kaushik ${ }^{1}$, Kristina Norne Widell ${ }^{3}$, Rasa Slizyte $^{3}$, Asha Kumari ${ }^{1,2}$

$4{ }^{1}$ Amity Food and Agriculture Foundation, Amity University Uttar Pradesh, Noida 201313, India

$5 \quad 2$ Amity Institute of Food Technology, Amity University Uttar Pradesh, Noida 201313, India

$6 \quad{ }^{3}$ SINTEF Ocean, Dep. Seafood Technology, 7465, Trondheim, Norway

11 Corresponding Author

12 Dr. Nutan Kaushik

13 Amity Food and Agriculture Foundation

14 Amity University Uttar Pradesh

$15 \quad$ Noida 201313

$16+919811392249$

$17 \quad$ Nkaushik5@amity.edu

18 kaushikn2008@gmail.com

19 


\section{Abstract}

21 Surimi industry produces large quantity of by-products as a combination of skin, bones, and

22 scale, which due to technical difficulty in separation, are being currently utilized for production

23 of low- value products such as biofertilizers and fish feed. Present paper focuses on utilization of

24 combined skin, bones, and scale from Pink Perch (Nemipterus japonicus) obtained from surimi

25 industry for gelatin extraction using single step process. Single step extraction method with

26 acetic acid and water was optimized using Response Surface Methodology (RSM) to maximize

27 yield and gel strength so that the process can be applied for sustainable utilization. Parameters

28 such as $\mathrm{pH}(\mathrm{A})$, extraction temperature (B) and extraction time (C) with respect to yield and L-

29 hydroxyproline content were optimized. Highest gelatin yield was obtained at $\mathrm{pH} 3,75^{\circ} \mathrm{C}$

30 extraction temperature, and 30 min extraction time. Gelatin yield and L-hydroxyproline content

31 under optimum condition were $16.2 \%$ and $41.62 \mathrm{mg} \cdot \mathrm{g}^{-1}$. The chemical composition, functional,

32 rheological, and structural properties of gelatin were examined and compared with commercial

33 bovine gelatin. Gelatin thus obtained at optimized condition exhibited high gel strength (793g)

34 and higher imino acid content (18.1\%) than bovine gelatin. FTIR spectra depicted high

35 similarities between both gelatin sample. Thus, the optimized method can be utilized for gelatin

36 extraction from Pink Perch by-products for development of high value products such as food

37 application.

38 Keywords: Gelatin, Pink Perch, RSM, by-product utilization, Nemipterus japonicus,

39 Rheological properties 


\section{$41 \quad 1 \quad$ Introduction}

42 Fish are the on the major sources of protein across the globe, leading to the expansion of fish

43 production from 86.9 MT in year 1986 to 96.4 MT in year 2018 (FAO, 2020), which has resulted

44 in an increase in the quantity of by-products generated. Approximately $40 \%$ of the harvested fish

45 is consumed during the processing while remaining nearly $60 \%$ of the fish are not utilized to its

46 full potential (Elavarasan et al., 2017). These by-products predominantly include head and

47 viscera, skin and bones trimmings, livers, roes etc. and they are either discarded or utilized in

48 production of low value product such as fish feed or fertilizers. This has led to serious ecological

49 threat due to high organic load and economical losses due to underutilization and loss of

50 nutritionally valuable materials. These by-products are rich source of commercially valuable

51 biomolecules such as proteins, gelatin, omega-3 polyunsaturated fatty acids, vitamins (A, D, E,

$52 \mathrm{~K}$ ), enzymes, bioactive peptides, amino acids etc. Therefore, currently many studies are being

53 conducted towards utilization of these by-products to exploit their full potential as high value

54 products is becoming global focus.

55 Gelatin is a protein based functional biopolymer produced from irreversible hydrolysis of

56 collagen molecules present in skin, bones, and scale of animals. It has a vast application in the

57 field of food, pharmaceuticals, photography, cosmetics, and biomedical application due to its

58 functional properties (Kumar et al., 2017). Conventionally, gelatin from mammalian source is

59 being utilized commercially. However, due to association of risk factors such as probability of

60 contraction of pathogenic infections such BSE (Bovine Spongiform Encephalopathy), prions and

61 foot and mouth disease and religious constraints, fish gelatin are now being considered as

62 suitable alternatives (Koli et al., 2012; Jin et al., 2019). In addition, fish derived gelatin are also

63 promising source of bioactive compounds exhibiting, antioxidant, anticancereous properties

64 (Tkaczewska et al., 2018; Mirzapour-Kouhdasht et al., 2020).

65 Though many studies have been conducted for extraction of gelatin from various fish by-

66 products (Martins et al., 2018; Zhang et al., 2020; Tan et al., 2019, Mi et al., 2019), very few

67 studies are available for combined biomass of skin, bones, and scales utilization. This study

68 utilizes combined biomass of skin, bones, and scale from surimi industry particularly from Pink

69 Perch, for extraction of good quality gelatin for utilization in food product development. Pink

70 Perch is a highly important commercial fish utilized in India for production of surimi due to its 
71 low cost, white and lean meat (Singh et al., 2005). In surimi production, a combination of skin,

72 bones and scale are produced as mixed by-products. The production process makes it impossible

73 to create separate by-products streams. Since conventional methods of production of high value

74 products such as gelatin involves use of skin and bones separately, the by-products from surimi

75 processing are commonly used for production of biofertilizers, fish feed or discarded due to

76 technical difficulty in separation of skin, bones, and scale combination industrially. Therefore,

77 development of technology for utilization of combined biomass of Pink Perch by-products for

78 gelatin production will provide eco-friendly and economically viable solution for industries.

79 Utilization of organic acid for extraction of gelatin is a cost-effective method. Additionally, the

80 method is environmentally sustainable, and the final products does not contain any toxic

81 chemical.

82 Therefore, objective of this study was to optimize gelatin extraction from combined biomass of

83 skin, bones, and scales from Pink Perch using Response Surface Methodology (RSM) to increase

84 the yield and properties of extracted gelatin. Subsequently, characterize the optimized gelatin for

$\mathbf{8 5}$ its rheological properties, functional properties and structural properties and compare with

86 commercial bovine gelatin (BG).

\section{Experimental}

\section{$\begin{array}{lll}88 & 2.1 & \text { Materials }\end{array}$}

89 The Pink Perch by-products (combination of skin, bones, and scales) were procured from Ulka

90 Seafood Pvt. Ltd, Mumbai in frozen condition $\left(-20^{\circ} \mathrm{C}\right)$ and stored at $-20^{\circ} \mathrm{C}$ until further use.

91 Gelatin from bovine source (Himedia) was used as control sample. All the reagent used were of

92 analytical grade.

\section{$93 \quad 2.2 \quad$ Measurement of Swelling Efficiency}

94 Swelling efficiency of Pink Perch by-products was analyzed according to method described by

95 Mirzapour-Kouhdasht et al., (2020). The swelling process was carried out at various pH values

$96(1-14)$ maintained using $0.1 \mathrm{~N} \mathrm{HCl}$ and $0.1 \mathrm{~N} \mathrm{NaOH}$. Mixture of skin, bones and scale was thawed 97 at room temperature $\left(25^{\circ} \mathrm{C}\right)$ for 30 minutes and weighed. The thawed mixture was then soaked in 98 various solutions of $\mathrm{pH}$ value ranging from 1-14 in ratio of 1:10 (w/v) and incubated at room 
99 temperature $\left(25^{\circ} \mathrm{C}\right)$ for 3 hours. The mixture was neutralized and washed with distilled water

100 before taking final weight. The swelling efficiency was calculated as-

101

$$
\text { SE }(\%)=\frac{\text { weight of sample after swelling }}{\text { weight of sample before swelling }} \times 100
$$

\subsection{Optimization of gelatin extraction}

103 Response Surface Methodology (RSM) was utilized to analyze the effects of independent

104 variable i.e., $\mathrm{pH}$, time, and temperature of gelatin extraction treatment in response to dependent

105 variable i.e., yield and L-hydroxyproline content of the gelatin. RSM is mathematical modeling

106 and statistical tool that interrelates extraction conditions and product attributes by establishing

107 regression equation. Design Expert Version 12.0 was used to obtained design experiment based

108 on Box-Behnken Design. Each independent variable varied at three levels $-1,0,+1$ (Table 1) and

10917 runs were obtained with 5 center points to minimize the error (Table 2).

110 Table 1

111 Experimental design of independent variables in Box-Behnken Design for gelatin extraction

112 from Pink Perch by-products.

\begin{tabular}{lllll}
\hline Independent & Symbols & Range & \\
\cline { 3 - 5 } Variable & & $\mathbf{- 1}$ & $\mathbf{0}$ & $+\mathbf{1}$ \\
pH & $\mathbf{A}$ & 3 & 6 & 9 \\
Temperature $\left({ }^{\circ} \mathbf{C}\right)$ & $\mathbf{B}$ & 25 & 50 & 75 \\
Time (min) & $\mathbf{C}$ & 30 & 135 & 240 \\
\hline
\end{tabular}

113

114 Table 2:

11517 experimental design points used for Pink Perch by-product gelatin extraction

\begin{tabular}{|c|c|c|c|}
\hline \multirow[t]{2}{*}{ Run } & \multicolumn{3}{|c|}{ Independent Variables } \\
\hline & pH (A) & $\begin{array}{l}\text { Temperature }\left({ }^{\circ} \mathrm{C}\right) \\
\text { (B) }\end{array}$ & Time (min) (C) \\
\hline 1 & 3 & 25 & 135 \\
\hline 2 & 9 & 50 & 30 \\
\hline
\end{tabular}




\begin{tabular}{llll}
\hline $\mathbf{3}$ & 6 & 75 & 30 \\
$\mathbf{4}$ & 3 & 50 & 240 \\
$\mathbf{5}$ & 6 & 50 & 135 \\
$\mathbf{6}$ & 3 & 50 & 30 \\
$\mathbf{7}$ & 9 & 50 & 240 \\
$\mathbf{8}$ & 6 & 50 & 135 \\
$\mathbf{9}$ & 6 & 50 & 135 \\
$\mathbf{1 0}$ & 6 & 75 & 240 \\
$\mathbf{1 1}$ & 9 & 25 & 135 \\
$\mathbf{1 2}$ & 3 & 75 & 135 \\
$\mathbf{1 3}$ & 6 & 25 & 240 \\
$\mathbf{1 4}$ & 6 & 25 & 30 \\
$\mathbf{1 5}$ & 6 & 50 & 135 \\
$\mathbf{1 6}$ & 6 & 50 & 135 \\
$\mathbf{1 7}$ & 9 & 75 & 135 \\
\hline
\end{tabular}

116

\section{$117 \quad$ 2.3.1 Process for gelatin extraction}

118 Figure 1 shows the process of gelatin extraction, from whole fish to freeze-dried gelatin.

119 Homogenous mass of Pink Perch by-products (25 g) was thawed and cut into small pieces of size

$1201 \mathrm{~cm}^{2}$. The cut pieces were mixed with distilled water in a ratio of 1:3 (w/v) and stirred at room

121 temperature $\left(25^{\circ} \mathrm{C}\right)$ for 10 minutes (Figure 1). Extraction process was carried out by subjecting

122 the mixture to 17 combinations of $\mathrm{pH}$ (3-9), temperature (25-75), time (30-240 minutes)

123 provided by RSM software. Glacial acetic acid and $4 \mathrm{M} \mathrm{NaOH}$ were used to adjust $\mathrm{pH}$ of the

124 aqueous solution. $\mathrm{pH}$ of the reaction mixture was neutralized to $\mathrm{pH}$ (6-6.5) after reaction using

125 glacial acetic acid or $4 \mathrm{M} \mathrm{NaOH}$. Afterwards the non-solubilized material was filtered. The

126 permeate solution containing solubilized gelatin was freeze dried.

127 


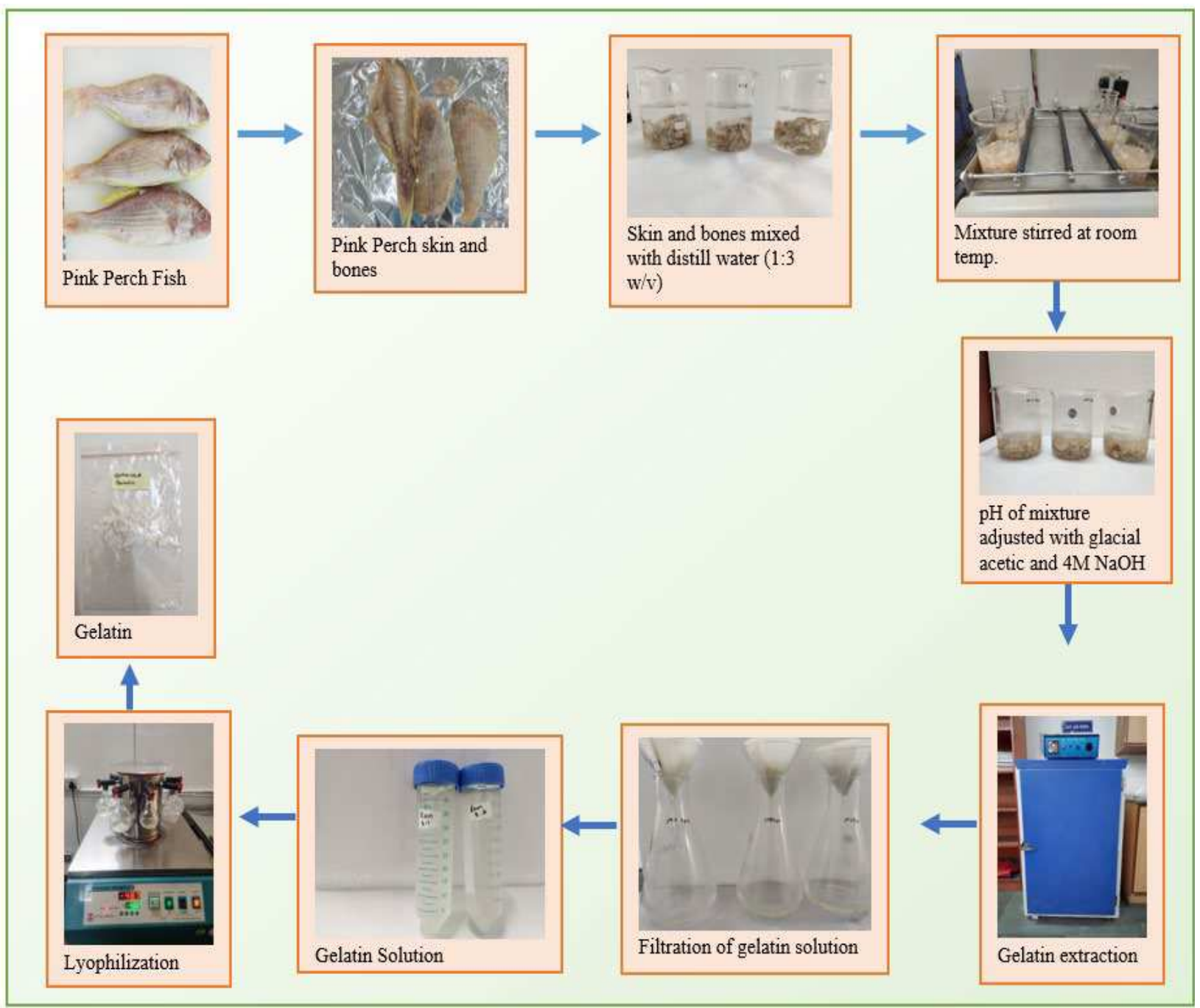

130 Fig 1. Schematic diagram of optimization of gelatin extraction from Pink Perch by-products 2.3.2 Yield

132 Yield of extracted gelatin was calculated as per using following equations -

$$
\text { Yield }(\%)=100 \times \frac{\text { Weight of lyophilised gelatin }(\mathrm{g})}{\text { Weight of initial fresh sample }(\mathrm{g})}
$$

\subsubsection{L- Hydroxyproline content}

135 L- Hydroxyproline (L- Hyp) content was estimated using the method of Koli et al., (2012). The

136 sample was hydrolyzed using $12 \mathrm{M} \mathrm{HCl}$ for 3 hours at $110^{\circ} \mathrm{C}$ and filtered. The filtrate was

137 neutralized using $1 \mathrm{M} \mathrm{NaOH}$ to a $\mathrm{pH}$ of 6.0-6.5. The neutralized sample $(0.1 \mathrm{~mL})$ was mixed with $1380.2 \mathrm{~mL}$ of isopropanol oxidant solution $(0.1 \mathrm{~mL}$ of the mixture of $7 \%$ chloramine $-\mathrm{T}$ and 
139 acetate/citrate buffer $\mathrm{pH} 6$ in a ratio of 1:4; v/v). Enhlrich's Reagent $(1.3 \mathrm{~mL})$ was added to the

140 mixture and incubated at $60^{\circ} \mathrm{C}$ for 30 minutes. Later it was cooled for 2-3 minutes, and volume

141 was made up to $5 \mathrm{~mL}$ using isopropanol. Absorbance was measured at $558 \mathrm{~nm}$ using

142 LMSPUV1000B, UV-VIS spectrophotometer (Labman Scientific Instruments Pvt.Ltd., India). L-

143 Hydroxyproline solution ranging from $0.01 \mathrm{mg} \cdot \mathrm{g}^{-1}$ to $0.1 \mathrm{mg} \cdot \mathrm{g}^{-1}$ was used as standard.

144 Hydroxyproline content was expressed in $\mathrm{mg}^{-\mathrm{g}^{-1}}$

145

146

147

148

149

150

151

152

153

154

155

156

157

158

159

160

161

162 For Texture profile analysis (TPA) gel sample were demolded from silicone tray. TA-XT Plus

163 texture analyzer (Stable Micro Systems, Surrey, UK) equipped with load cell of $50 \mathrm{~kg}$ was used 164 to conduct TPA. A $75 \mathrm{~mm}$ diameter probe was used to compress gelatin gel twice to $40 \%$ of its

165

166

\subsection{Characterization of the Gelatin}

\subsubsection{Proximate Analysis}

Proximate composition of gelatin was determined as per standard methods of AOAC. For moisture content determination $1 \mathrm{~g}$ of gelatin was oven dried at $105^{\circ} \mathrm{C}$ for 24 hours and final weight was recorded after cooling down the dried sample in desiccator. Ash content was estimated by keeping the moisture free sample in muffle furnace at $600^{\circ} \mathrm{C}$ for 24 hours for dry ashing. Fat content was analyzed using Soxhlet method. Initial and final weights were recorded. Total nitrogen content $(\mathrm{N})$ was estimated by $\mathrm{CHN}-\mathrm{S} / \mathrm{N}$ elemental analyzer 1106 (Costech Instruments ECS 4010 CHNSO Analysator). Protein content was subsequently calculated using factor of 5.55 (Kurl, 2019).

\subsubsection{Gel Strength and Texture Profile Analysis}

Gelatin $(6.67 \mathrm{~g})$ was mixed with $100 \mathrm{~mL}$ distilled water using a water bath at $60^{\circ} \mathrm{C}$ until completely dissolved. $10 \mathrm{~mL}$ of gelatin solution was transferred to silicone tray and refrigerated at $4{ }^{\circ} \mathrm{C}$ for $16-18$ hours for maturation. Gel strength measurements was carried out using TA- XT Plus texture analyzer (Stable Micro Systems, Surrey, UK) attached with a 5KN load cell. The force required to penetrate cylindrical flat bottom probe $(12.7 \mathrm{~mm}$ diameter) to $4 \mathrm{~mm}$ in gelatin sample at a speed of $1 \mathrm{~mm} / \mathrm{s}$ was considered as a gel strength in $\mathrm{g}$. 65 original height as an imitation of chewing process. The time duration between first and second 66 compression was $5 \mathrm{sec}$. Textural parameters such as hardness (g), cohesiveness, adhesiveness 
167 (g.sec), springiness and chewiness were calculated by Exponent Connect software provided 168 along with the instrument.

\section{$169 \quad 2.4 .3 \quad$ Rheological Measurements}

170 For rheological measurement $6.67 \%$ gelatin solution was prepared to $60^{\circ} \mathrm{C}$ until completely

171 dissolved. Mixture was matured at $4{ }^{\circ} \mathrm{C}$ for $16-18$ hours. The elastic modulus $\left(\mathrm{G}^{\prime}\right)$ and loss

172 modulus (G',) was recorded for gelatin gels using Anton Paar Germany GmbH, MCR 52

173 modular compact rheometer. Strain sweep of gelatin gels was conducted at a frequency of $1 \mathrm{~Hz}$ at

$1745^{\circ} \mathrm{C}$ for $0.1 \%$ to $10 \%$ strain to determine the linear viscoelastic region of sample. The

175 temperature sweep test was conducted from $5^{\circ} \mathrm{C}$ to $35^{\circ} \mathrm{C}$ and $35^{\circ} \mathrm{C}$ to $5^{\circ} \mathrm{C}$. During the test a scan

176 rate of $1^{\circ} \mathrm{C} / \mathrm{min}, 1 \mathrm{~Hz}$ frequency and $3 \mathrm{~Pa}$ stress was maintained. The temperature corresponding

177 to crossover point of G' and G', during heating and cooling of gelatin sample were defined as

178 melting and gelling points respectively. Frequency sweep test was done to analyze stability and

179 structure of gelatin gel. The test was conducted at $5^{\circ} \mathrm{C}$ between 0.01 and $100 \mathrm{~Hz}$ and $3 \mathrm{~Pa}$ stress.

180 The time sweep test was performed for 30 minutes at a temperature of $5^{\circ} \mathrm{C}$ at a frequency of

$1811 \mathrm{~Hz}$ and 200 pa stress.

\section{$182 \quad$ 2.4.4 Water Holding and Fat Binding Capacity}

183 Water holding and fat binding capacity was determined as per the method of Jin et al., (2019)

184 with slight modification. Estimation of water holding capacity was conducted by adding $100 \mathrm{mg}$ 185 of the lyophilized gelatin powder to $1000 \mu \mathrm{L}$ of distilled water and allowing to stand for 1 hour 186 at ambient temperature $\left(25^{\circ} \mathrm{C}\right)$. The suspension was centrifuged at $6000 \times \mathrm{g} \mathrm{rpm}$ for 20 minutes at $18725^{\circ} \mathrm{C}$. The upper layer was decanted by allowing the tube to stand at $45^{\circ} \mathrm{C}$ for 30 minutes.

188 Weight of residue was noted. Fat binding capacity was calculated by replacing distilled water 189 with $1000 \mu \mathrm{L}$ sunflower oil.

$190 \quad$ 2.4.5 Foaming Capacity and Foam Stability

191 Foam expansion and foam stability was determined as per method of Dara et al., (2020) with

192 slight modification. Gelatin solution of different concentration $(0.1 \%, 0.5 \%, 1 \%)$ was prepared 193 and homogenized for 2 minutes at room temperature $\left(25^{\circ} \mathrm{C}\right)$. Aliquot was immediately 194 transferred to $50 \mathrm{~mL}$ measuring cylinder and volume of whipped sample was recorded. The 195 aliquot was allowed to stand for 30 minutes at room temperature and volume was recorded. 
196 The foam expansion and foam stability were calculated as follows-

$$
\begin{aligned}
& \text { Foam Expansion(\%) }=\frac{V_{t}-V_{\mathbf{o}}}{V_{\mathbf{o}}} \times 100 \\
& \text { Foam Stability }(\%)=\frac{V_{T}-V_{o}}{V_{o}} \times 100
\end{aligned}
$$

199

200 Where-

$201 V_{0}$ was total volume before homogenization

$202 V_{t}$ was total volume after homogenization

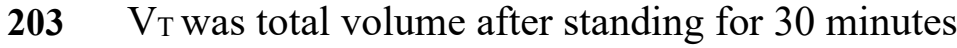

\section{$204 \quad$ 2.4.6 Emulsion Activity Index and Emulsion Stability Index}

205 The emulsion activity and emulsion stability were evaluated as per method of Dara et al., (2020).

206 Gelatin solution of various concentration $(0.1 \%, 0.5 \%, 1 \%)$ were prepared. $30 \mathrm{~mL}$ of gelatin

207 solution was homogenized with $10 \mathrm{~mL}$ of sunflower oil for 1 minute. A $50 \mu \mathrm{L}$ aliquot was drawn

208 from the bottom of the emulsion at 0 minute and 10 minutes and diluted with $5 \mathrm{~mL}$ of $0.1 \%$ of

209 SDS solution. Absorbance of the solution was read at $500 \mathrm{~nm}$ using LMSPUV1000B, UV-VIS

210 spectrophotometer (Labman Scientific Instruments Pvt.Ltd., India) immediately after 0 minute 211 and 10 minutes.

212 Emulsion Activity Index (EAI) and Emulsion Stability Index (ESI) were calculated using

213 following equation-

$$
\text { EAI }\left(\mathrm{m}^{2} \cdot \mathrm{g}^{-1}\right)=\frac{2 \times 2.303 \times \mathrm{A500} \mathrm{nm}}{0.25 \times \operatorname{gelatin} w e i g h t(g)}
$$

215

$$
\operatorname{ESI}(\min )=\frac{\mathbf{A}_{\mathbf{o}} \times \Delta \mathbf{t}}{\Delta \mathbf{A}}
$$

217

218 Where, $\Delta \mathrm{A}=$ Absorbance at $0 \min \left(\mathrm{A}_{\mathrm{o}}\right)-\mathrm{Absorbance}$ after $10 \min (\mathrm{A} 10)$ and $\Delta \mathrm{t}=10 \mathrm{~min}$ 
220 Color of gelatin was estimated by NS810 portable spectrophotometer (Shenzhen Threenh

221 Technology Co., Ltd., China) by employing CIE color system for evaluating L* (Lightness), a*

222 (redness/greenness), b* (yellowness/greenness) values. $\mathrm{h}^{*}$ (hue) and $\mathrm{C} *$ (Chroma) were also

223 obtained using color analyzer.

224

225

226

227

228

229

230

231

232

233

234

235

236

237

238

239

240

241

242

243

246

244 scanning electron microscopy. 2-3 $\mathrm{mm}$ thick gelatin samples were initially fixed with 245 glutaraldehyde $(2.5 \%, \mathrm{v} / \mathrm{v})$ in presence of $0.2 \mathrm{M}$ phosphate buffer of $7.2 \mathrm{pH}$ for a time period of

\subsubsection{Amino Acid Analysis}

The amino acid composition of gelatin was determined by using High Performance Liquid Chromatography (HPLC) as per the method of Osnes and Mohr, (1985) with slight modification. $50 \mathrm{mg}$ of gelatin were weighed in a screw cap bottle and mixed with $2 \mathrm{~mL}$ of $6 \mathrm{M} \mathrm{HCl}$. The tubes were incubated for 24 hours at $110^{\circ} \mathrm{C}$. After completion of hydrolysis $\mathrm{pH}$ of the mixture was neutralized and it was filtered using Whatman glass microfiber filters $(55 \mathrm{~mm})$. Volume of the filtrate was made-up up to 5mL using milli-Q water. The HPLC system (Agilent Infinity 1260, Agilent Technologies) was coupled to an on-line-post-column derivatization module (Pinnacle

32 PCX, Pickering laboratories, Mountain View, CA, USA) using ion exchange column (4.6 x 110 $\mathrm{mm}, 5 \mathrm{~mm}$ ) and OPA and FMOC as derivatizing reagent. Standard curves measured with amino acid standards were used to quantify standard amino acids.

\subsubsection{FTIR Analysis}

FT-IR spectra of gelatin was obtained by using Nicolet FTIR 6700 (Thermo Fisher Scientific, US). $5 \mathrm{mg}$ of dried sample was mixed with potassium bromide to form homogeneous powder. The powder was mounted on the equipment and converted into pellets after subjecting to pressure applied by hydraulic press. The pressed pellets were then analyzed in the region of $4000-500 \mathrm{~cm}^{-1}$ with $4 \mathrm{~cm}^{-1}$ resolution to determine the presence to of various functional groups. Background corrections were carried out before analysis of samples.

\subsubsection{SEM Analysis}

Microstructure of $6.67 \%$ gelatin gels was visualized using Zeiss (MA EVO -18 Special Edition) $4612 \mathrm{~h}$. These samples were subsequently rinsed with distilled water and dehydrated using ethanol. 
247 Dehydrated samples were mounted on bronze stub and coated with gold and palladium in a

248 process called gold sputtering. This process was carried for 4 minutes. And samples were

249 observed at an acceleration voltage of $20 \mathrm{kv}$.

\section{$250 \quad 2.5 \quad$ Statistical Analysis}

251 All the experiments were conducted in triplicates. Mean and standard deviation were calculated 252 using Microsoft Office Excel 2016. Statistical analysis of data was carried out using the IBM

253 SPSS (Version 26.0). The data presented in the study was analyzed by one-way analysis of 254 variance (ANOVA) The Duncan's multiple range test was used to determine the significance of 255 mean differences. The significant level in the present study was set at $\mathrm{p}<0.05$

\section{Results and discussion}

\section{$257 \quad 3.1 \quad$ Measurement of Swelling Efficiency}

258 Swelling efficiency of by-products is a very crucial factor in determining intensity of pre259 treatment required for gelatin production from fish. Swelling efficiency is primarily affected by 260 absorption caused by collagen present in skin, bones, and scale. High swelling efficiency 261 indicates high interaction of collagen molecules with the external medium resulting in less 262 resistance and lower interference from surrounding biomolecules during absorption of water or 263 other external medium (Mirzapour-Kouhdasht et al., 2020). Therefore, a higher swelling 264 efficiency implies higher possible yield of gelatin. In this study higher swelling efficiency was 265 observed at acidic $(\mathrm{pH}<3)$ and alkali $(\mathrm{pH}>10) \mathrm{pH}$ in comparison to neutral $\mathrm{pH}$ conditions (Figure 266 2). A sharp decline in swelling property was being observed at highly alkali and acidic condition 267 which can be due to fragmentation of protein into smaller peptides. 


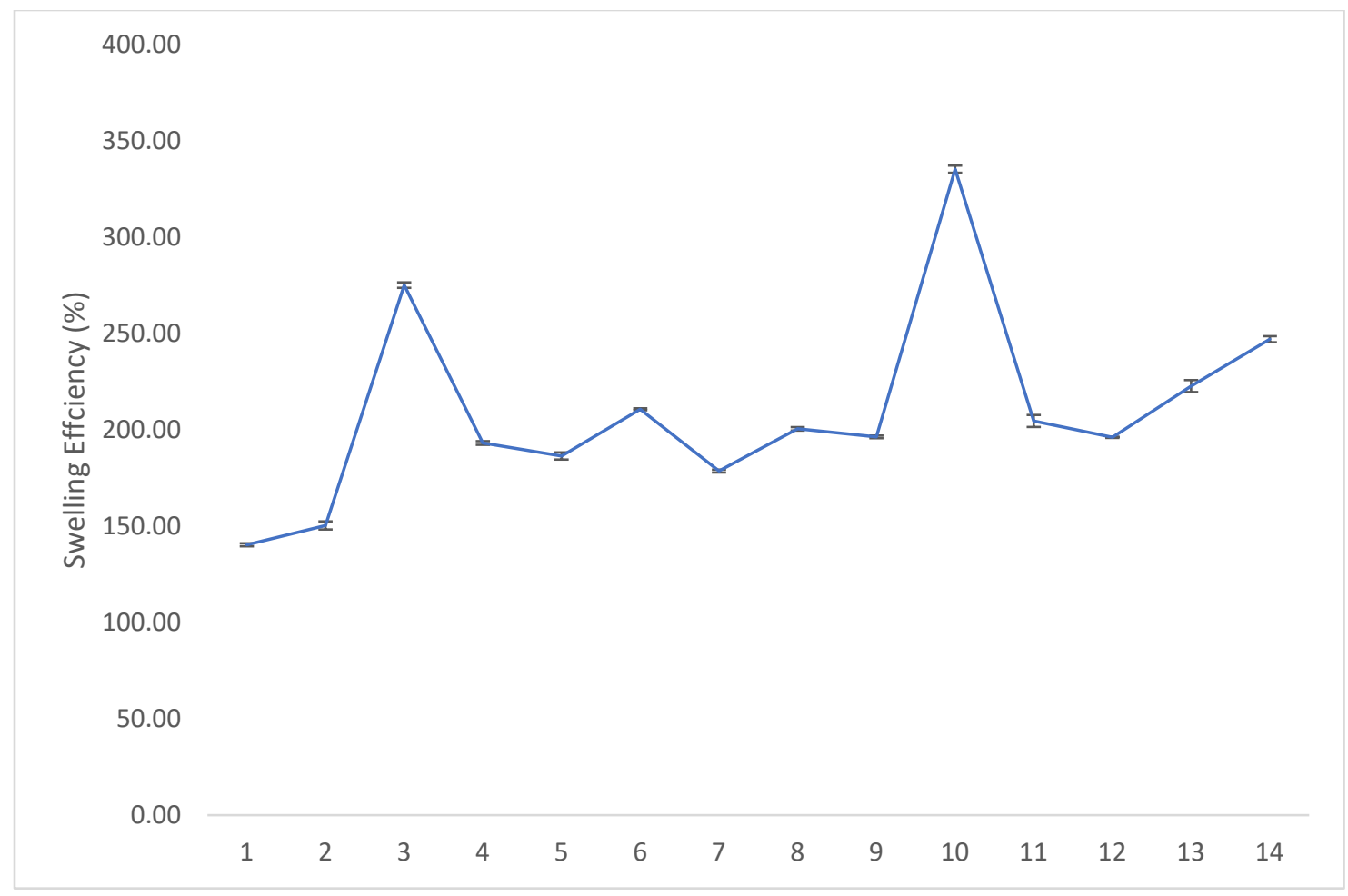

269 Fig. 2. The effect of $\mathrm{pH}$ on swelling efficiency of by-products of Pink Perch

\section{$271 \quad 3.1$ Optimization of gelatin extraction}

272 Quality of gelatin depends on nature, source of raw material, and yield, but also on extraction

273 parameters. Therefore, optimization of extraction parameters is required to maximize the

274 efficiency of extraction process. In this study, RSM was employed to obtain the optimum 275 condition for gelatin extraction from Pink Perch by-products.

276 Box-Behnken Design with three independent variables $(\mathrm{pH}$, temperature, and time) was followed 277 to study yield and L-hydroxyproline as response variable. Regression analysis was performed for 278 all responses. Models obtained by RSM for yield and L-hydroxyproline content of gelatin was 279 statistically significant. High $\mathrm{R}^{2}$ value was obtained for both the models.

\section{$280 \quad$ 3.1.1.1 Yield}

281 From commercial point of view, obtaining maximum yield is a prime objective for any 282 extraction method. In this study, gelatin yield obtained at 17 combinations provided by RSM283 BBD was in range of $0.03 \%-13.06 \%$ (Figure 3). A quadratic relationship was observed between 
284 extraction parameters and gelatin yield. Regression equation for prediction of maximum yield

285 obtained from RSM is provided at equation 1. The model was found to be significant with p-

286 value $<0.001$. A high $p$-value of lack of fit implies that quadratic model was adequate. The

287 results from ANOVA suggested that gelatin yield was significantly influenced by all the

288 independent variables i.e., $\mathrm{pH}(\mathrm{A})$, temperature $(\mathrm{B})$ and time $(\mathrm{C})$ and their interactions $(\mathrm{p}<0.001)$.

$289 \mathrm{R}^{2}$ value (0.99) obtained from analysis of variance signifies that model was capable of

290 sufficiently explaining the system. Optimum condition for extraction of maximum gelatin yield

$291(16.2 \%)$ obtained from RSM was observed to be $\mathrm{pH} 3$, time 30 minutes and temperature $75^{\circ} \mathrm{C}$.

292 Verification of predicted gelatin yield obtained from model was done by conducting gelatin

293 extraction at optimum condition in triplicates. Experimental yield (16.2\%) obtained after

294 performing extraction at optimum condition was close to predicted value (16.9\%) (Table 3).

295 Gelatin yield obtained in this study was higher than previous reported studies such Mafazah et

296 al., (2018) reported a yield of 8.4\%- 12.49\% from Yellowfin Tuna fish skin and Hue et al.,

297 (2017) reported yield in the range of 10.2- 13.8\% from European perch and Volga Pikeperch

298 skins.

299 Yield $=24.20223-6.22941 \mathrm{~A}+0.107592 \mathrm{~B}-0.063355 \mathrm{C}-0.008217 \mathrm{AB}+0.008698 \mathrm{AC}-0.000162 \mathrm{BC}$

$300+0.353292 \mathrm{~A}^{2}+0.000615 \mathrm{~B}^{2}+0.000040 \mathrm{C}^{2}$

Equation 1

301 Where, $\mathrm{A}=\mathrm{pH}, \mathrm{B}=$ Temperature $\left({ }^{\circ} \mathrm{C}\right)$ and $\mathrm{C}=$ Time (min) 


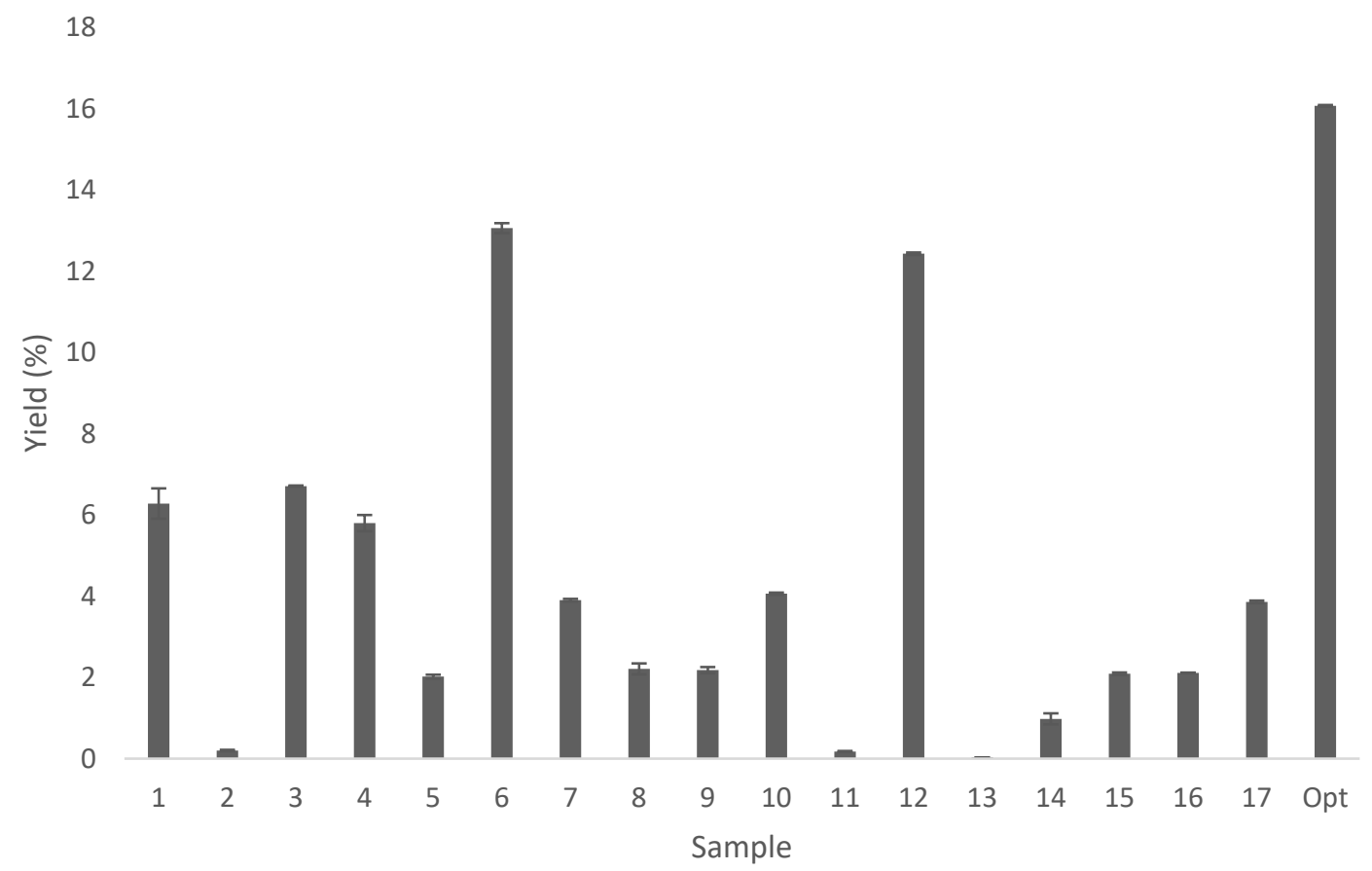

302

$303 \quad$ Fig 3: Yield of gelatin from Pink Perch by-products obtained at different RSM combinations and

304 optimum condition. Condition for extractions of 1-17 is presented in table 2 and for optimum

305 condition is presented in table 3

306 Table 3

307 Predicted and experimental values of percentage yield and L-Hydroxyproline content (L-Hyp) of

308 gelatin from Pink Perch by-products at optimized condition

\begin{tabular}{|c|c|c|c|c|c|c|}
\hline $\begin{array}{l}\text { pH } \\
\text { (A) }\end{array}$ & $\begin{array}{l}\text { Temperature } \\
\left({ }^{\circ} \mathrm{C}\right) \\
\text { (B) }\end{array}$ & $\begin{array}{l}\text { Time } \\
(\min ) \\
\text { (C) }\end{array}$ & $\begin{array}{l}\text { Predicted } \\
\text { Value (Yield } \\
\%)\end{array}$ & $\begin{array}{l}\text { Optimized } \\
\text { Value (Yield } \\
\%)\end{array}$ & $\begin{array}{l}\text { Predicted } \\
\text { Value (L- } \\
\left.\text { Hyp, } \text { mg.g }^{-1}\right)\end{array}$ & $\begin{array}{l}\text { Optimized } \\
\text { Value (L- } \\
\text { Hyp, mg.g }\end{array}$ \\
\hline 3 & 75 & 30 & 16.9 & 16.2 & 39.99 & 41.62 \\
\hline
\end{tabular}

\subsubsection{L-Hydroxyproline}

311 A linear relationship was observed between L-hydroxyproline content and independent variables

312 ( $\mathrm{pH}$, extraction temperature and extraction time) from RSM. L hydroxyproline content obtained

313 at $17 \mathrm{RSM}$ combination ranged from $2.78-43.77 \mathrm{mg} \cdot \mathrm{g}^{-1}$ (Figure 4). Regression equation 2 was 
314 obtained to predict L-hydroxyproline content using this model. Analysis of variance of response

315 surface model for L-hydroxyproline suggested that the model was highly significant with p-value

$316<0.01$. It was observed that L-hydroxyproline content of gelatin was significantly influenced by

317 the independent variables i.e., $\mathrm{pH}$, and temperature with $\mathrm{p}<0.05$. However, interaction of various

318 extraction factor did not produce any significant effect on L-hydroxyproline content. Verification

319 of predicted value was conducted in triplicates at optimum condition $\left(\mathrm{pH} \mathrm{3,} \mathrm{temperature} 75^{\circ} \mathrm{C}\right.$

320 and time 30 minutes). Predicted value of L-hydroxyproline content based on RSM analysis

321 (39.99 $\left.\mathrm{mg} \cdot \mathrm{g}^{-1}\right)$ was close to the experimental value of gelatin extracted from $\left(41.62 \mathrm{mg} \cdot \mathrm{g}^{-1}\right)($ table

322 3). L-hydroxyproline of Pink Perch by-products gelatin obtained at optimum condition was

323 significantly higher than control bovine gelatin $\left(34.97 \mathrm{mg}^{-g^{-1}}\right)(\mathrm{p}<0.05)$.

324 L-Hydroxyproline $=0.360768-0.127475 \mathrm{~A}+0.054344 \mathrm{~B}-0.001946 \mathrm{C}$

Equation 2

325 Where, $\mathrm{A}=\mathrm{pH}, \mathrm{B}=$ Temperature $\left({ }^{\circ} \mathrm{C}\right)$ and $\mathrm{C}=$ Time (min)

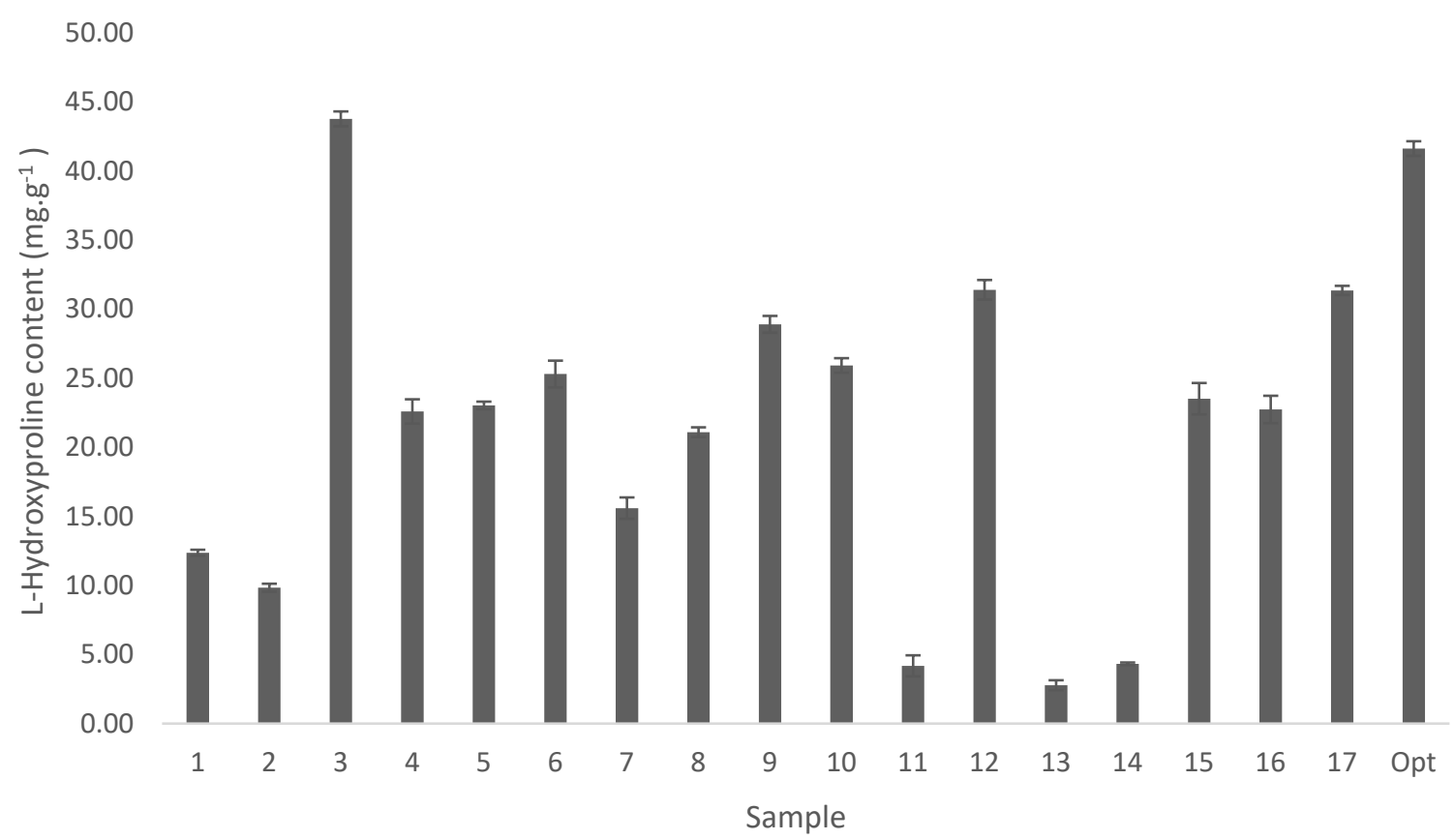

327 Fig. 4. L-hydroxyproline content of gelatin from Pink Perch by-products obtained at different 328 RSM combinations. Condition for extractions of 1-17 is presented in table 2 and for optimum 329 condition is presented in table 3. 


\section{$330 \quad$ 3.1.1.3 Response surface plots}

331 A three-dimensional response surface plots of effects of independent variables $(\mathrm{pH}$, extraction

332 temperature and extraction time) on dependent variable (yield and L-hydroxyproline content) are

333 shown in Figure $5 \& 6$. The graphs are plotted as a function of two factors at a time and keeping

334 the third factor fixed at middle level. From plots it was observed that as the level value of

335 extraction time and $\mathrm{pH}$ decreased, gelatin yield and L-hydroxyproline content increased and

336 increase in extraction temperature led to increase in gelatin yield and L-hydroxyproline content.

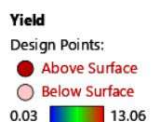

$0.03 \longrightarrow 13.06$

Yield $=6.28$

Std \#1 Run \#11

$\mathrm{X} 2=\mathrm{B}:$ Temperature $=25$

Actual Factor

C: Time $=135$

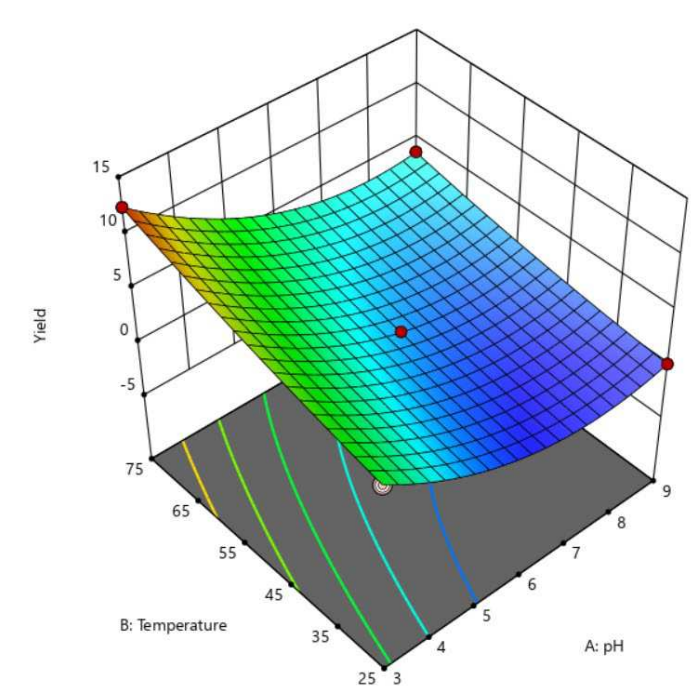

338

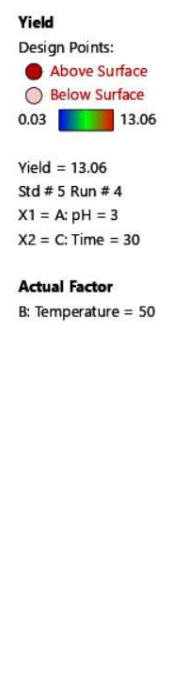

(a)

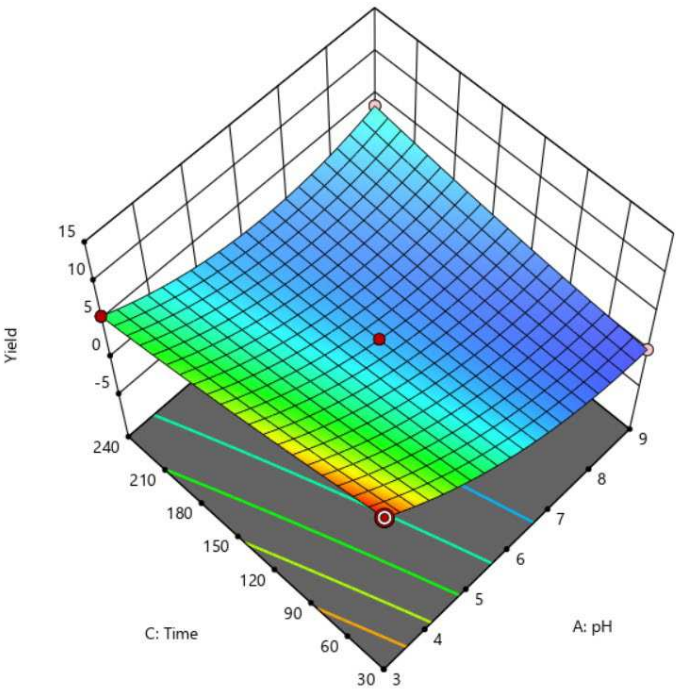

(b)
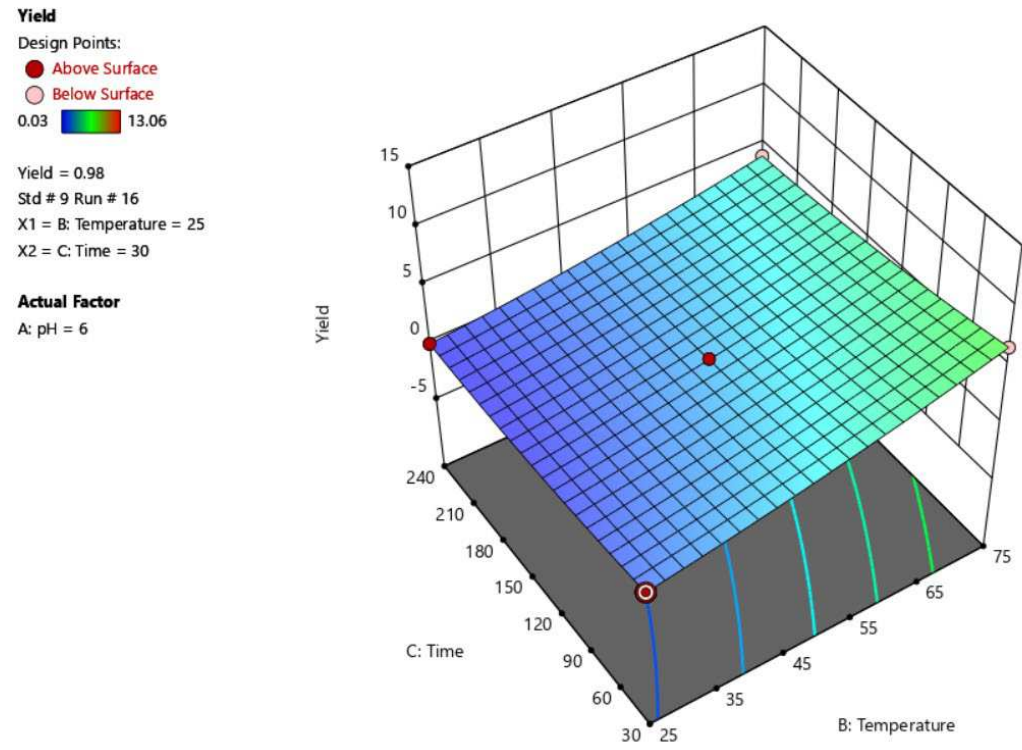

(c) 
341 Fig. 5. 3- D surface graph of gelatin yield from Pink Perch by-products as a function of (a)

342 temperature vs $\mathrm{pH}$, (b) time vs $\mathrm{pH}$, (c) time vs temperature

343

344

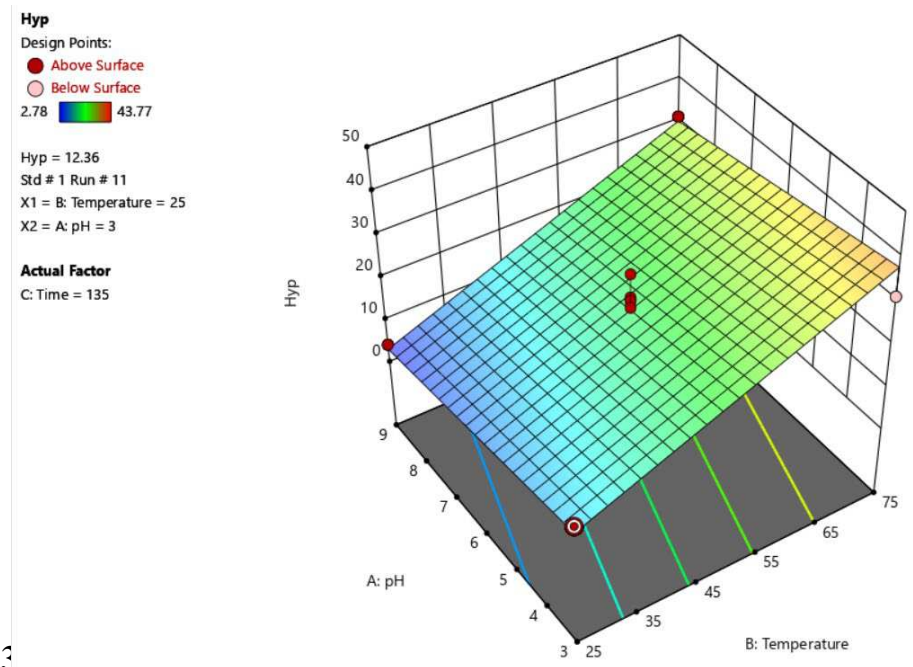

346

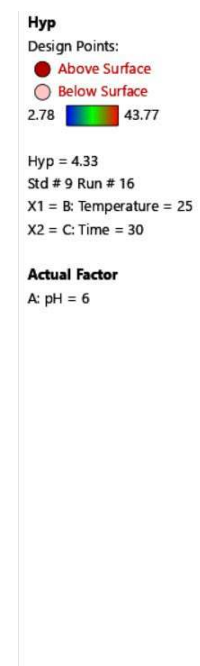

(a)

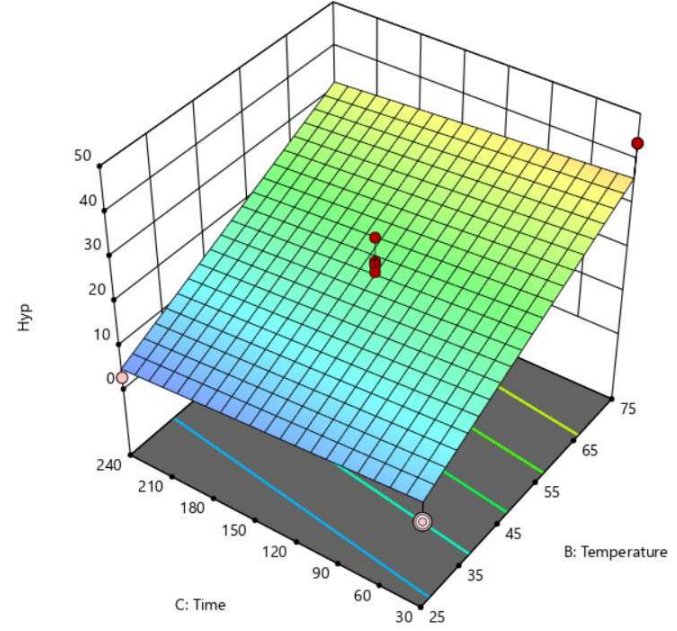

(b)

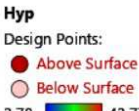

Below Surface

Hyp $=25.3$

Std \# 5 Run \# 4

$\mathrm{X} 1=\mathrm{A} ; \mathrm{PH}=3$

$\mathrm{X} 2=\mathrm{C}:$ Time $=30$

Actual Factor

B: Temperature $=50$

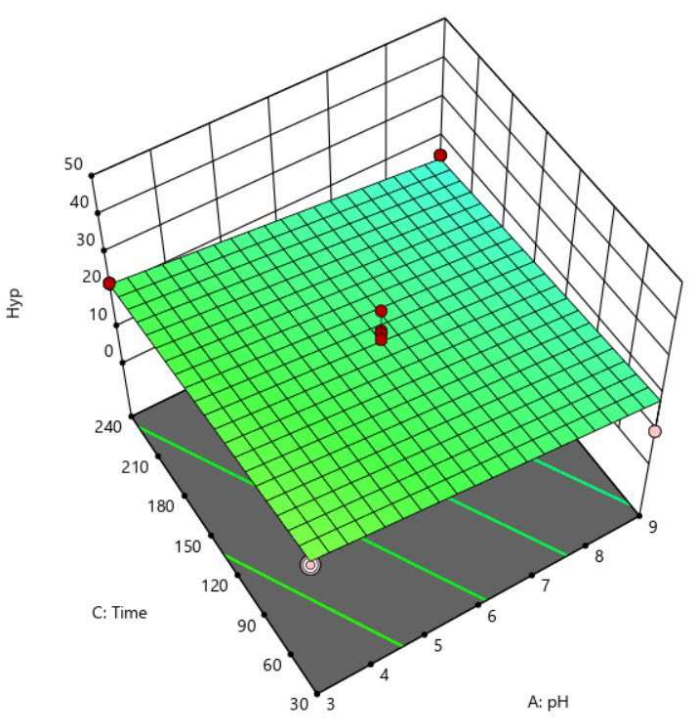

(c)

349 Fig. 6. 3-D Graph of L-Hydroxyproline content of gelatin from Pink Perch by-products as a

350 function of (a) $\mathrm{pH}$ vs time, (b) time vs temperature and (c) $\mathrm{pH}$ vs temperature 


\subsection{Proximate composition of the extracted gelatin}

352 Gelatin obtained at optimized condition was observed to have moisture content of $4.79 \pm 1.45 \%$

353

354

355

356

357

358

359

360

361

362

363

364 Table 4

365 Proximate analysis of Pink Perch by-products gelatin from optimized condition and bovine 366 gelatin

\begin{tabular}{lllll}
\hline Gelatin & Ash (\%) & Moisture (\%) & Fat (\%) & Protein (\%) \\
\hline Bovine Gelatin & $0.89 \pm 0.38$ & $12.11 \pm 0.02$ & $3.36 \pm 0.17$ & $83.44 \pm 1.14$ \\
Optimized & $2.56 \pm 0.10$ & $4.79 \pm 1.45$ & $0.13 \pm 0.02$ & $92.06 \pm 0.99$ \\
Gelatin & & & &
\end{tabular}

367 Values are means \pm standard deviation $(\mathrm{n}=3)$

\section{$368 \quad 3.3 \quad$ Gel Strength}

369 Gel strength is one of defining characteristics of gelatin and hence it also acts as a quality 370 indicator. On the basis of gel strength gelatins are classified into 3 categories low bloom $(<150$ $371 \mathrm{~g})$, medium bloom (150-220 g) and high bloom (220-300 g). In this study high bloom gelatin 372 was obtained from PG with gel strength of $793 \mathrm{~g}$, significantly higher than gel strength of 373 medium bloom BG (167g) (Table 5). Gel strength of gelatin are influenced by various intrinsic 374 and extrinsic factors such as extraction parameters, amino acid profile, imino acid content and 
375 band intensities of $\beta$ - and $\gamma$ - chains. Gelatin forms a thermally reversible gel networks majorly

376 stabilized by hydrogen bonds. These hydrogen bond formations are predominantly contributed

377 by L-hydroxyproline via interaction with carbonyl group and bonding with water molecules.

378 This was also demonstrated in this study where high gel strength of Pink Perch by-products

379 gelatin was coincidental with high L- hydroxyproline content. Different studies have reported

380 different gel strength of gelatin obtained from different fish such as yellow fin tune (426 g) (Cho

381 et al., 2005), silver carp skin gelatin (770g) (Boran et al., 2010).

382 TPA tests of PG and control BG was done at $6.67 \%(w / v)$ concentration (Table 5). Generally, 383 good gelatins are characterized by higher gel strength and TPA values (for hardness,

384 cohesiveness, adhesiveness, springiness, and chewiness) (Yang et al., 2007). Hardness is defined

385 as measure of strength of internal gel structure when subjected to compression. It is also referred

386 as the force required to attain a certain deformation in gel structure. Hardness of PG (11.25 \pm

$3871.11 \mathrm{~N})$ was significantly higher than $\mathrm{BG}(5.15 \pm 0.28 \mathrm{~N})(\mathrm{p}<0.05)$. Cohesiveness is a measure of

388 strength required to disrupt the internal structure of gel before absolute deformation. It is also an

389 indicator of extent to which gelatin is able to withstand second compression in relation to first

390 compression. Among both the samples tested PG showed significantly higher cohesiveness value

$391(0.89 \pm 0.01)$ than $\mathrm{BG}(0.78 \pm 0.01)(\mathrm{p}<0.05)$. Adhesiveness in food products represents the

392 amount of negative force area required for the first bite. It can be used to predict the degree of

393 work necessary to overcome adhesion between food particle and teeth. PG showed similar

394 adhesiveness value to BG. Springiness is defined as height recovered by food during timelapse

395 between end of first bite and beginning of second bite. It is also called elasticity. Higher

396 springiness in PG is indicative of formation of large pieces during TPA compression and lower

397 springiness in BG might have resulted for formation of smaller pieces during TPA compression.

398 Chewiness is defined as the product of hardness, cohesiveness, and springiness. It is a

399 representative of energy required to masticate food product before swallowing. Chewiness value

400 of PG was observed to be higher than BG. From TPA of both the sample it was evident that

401 textural properties of PG were comparable to control BG.

402 
404 Table 5:

405 Textural properties of Pink Perch by-products gelatin (PG) and bovine gelatin (BG)

\begin{tabular}{lll}
\hline Textural Parameter & PG & BG \\
\hline Gel Strength(g) & $793.01 \pm 0.99$ & $167 \pm 1.00$ \\
Hardness (N) & $11.25 \pm 1.11$ & $5.15 \pm 0.28$ \\
Adhesiveness (g.sec) & $-17.08 \pm 3.78$ & $-11.72 \pm 1.05$ \\
Springiness & $0.91 \pm 0.01$ & $0.78 \pm 0.01$ \\
Cohesiveness & $0.89 \pm 0.01$ & $0.75 \pm 0.01$ \\
Chewiness & $8.16 \pm 0.94$ & $3.89 \pm 0.21$ \\
\hline
\end{tabular}

Values are means \pm standard deviation $(n=3)$

\section{$407 \quad 3.4 \quad$ Rheological Measurements}

408 Figure 7 illustrates results from strain sweep test of PG and BG at $5^{\circ} \mathrm{C}$. Strain sweep test was

409 performed to estimate viscoelastic region of gelatin gel at $5^{\circ} \mathrm{C}$. Results indicated that both the

410 gelatin sample had higher storage modulus as compared to loss modulus, which leads to

411 formation of stronger three-dimensional structure in gelatin. However, PG storage modulus was

412 even higher than BG suggesting better gelling properties. 


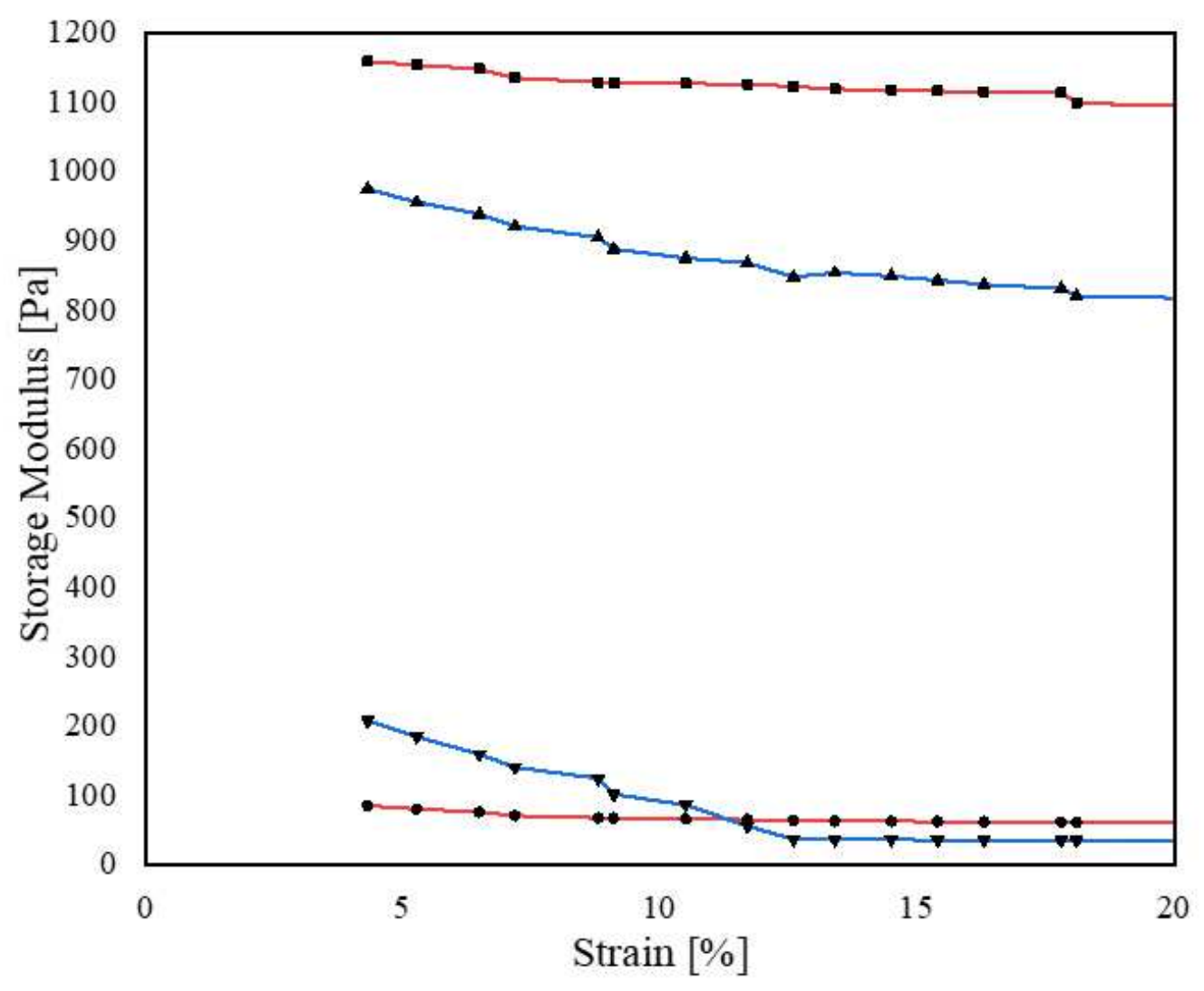

414 Fig 7: Storage modulus $\left(\mathrm{G}^{\prime}\right)$ (square symbols) and loss modulus (G") (triangle symbols) as a 415 function of strain during a strain sweep at cooling for Pink Perch by-products gelatin (Red) and 416 bovine gelatin (Blue)

418 Cooling scan of PG and BG depicted a similar behavior of visco-elastic property (Figure 8). Both 419 storage $\left(G^{\prime}\right)$ and loss $\left(G^{\prime}\right.$ ') modulus for PG and BG increased linearly, followed by sharp 420 increase in the curve between temperature of $16^{\circ}-5^{\circ} \mathrm{C}, 16^{\circ}-5^{\circ} \mathrm{C}$ and $19^{\circ}-15^{\circ}, 19^{\circ}-15^{\circ} \mathrm{C}$ 421 respectively. Steep rise of G' and G' curves are observed during of gelation due to thermal 422 transitioning during which gel networks are formed rapidly. Gelling temperature is determined 423 by cross-over point of $G^{\prime}$ and $G$ ', curve in cooling scan of gelatin. Gelling temperature for PG 424 and $\mathrm{BG}$ were $18.16^{\circ} \mathrm{C}$ and $20.1^{\circ} \mathrm{C}$ respectively.

425 Similarly, during heating scan both the gelatins indicated a steep rise in $G^{\prime}$ and G' in 426 temperature range of $13^{\circ}-25^{\circ} \mathrm{C}, 13^{\circ}-25^{\circ} \mathrm{C}$ and $13^{\circ}-25^{\circ} \mathrm{C}, 15^{\circ}-25^{\circ} \mathrm{C}$ respectively (Figure 8). A 427 sharp decrease of G' and G' 'in heating scan indicated the period during which gelatin is 
428 undergoing thermal transition to form solution from gel state. Melting temperature is also taken

429 as the cross-over point of $G^{\prime}$ and $G^{\prime}$ ' curve in heating scan of gelatin. Melting temperature as

430 observed from Figure 8 (c) and (d) for PG and BG were $24.83^{\circ} \mathrm{C}$ and $24.49^{\circ} \mathrm{C}$ respectively.

431 Similar results were reported by Abdelhedi et al., (2017) for gelling $\left(19.4^{\circ} \mathrm{C}\right)$ and melting

432 temperature $\left(25.3^{\circ} \mathrm{C}\right)$ of gelatin from black-barred halfbeak skin. He also mentioned that typical

433 range for gelling and melting temperature of fish gelatin is 8 to $25^{\circ} \mathrm{C}$ and 11 to $28^{\circ} \mathrm{C}$.

434

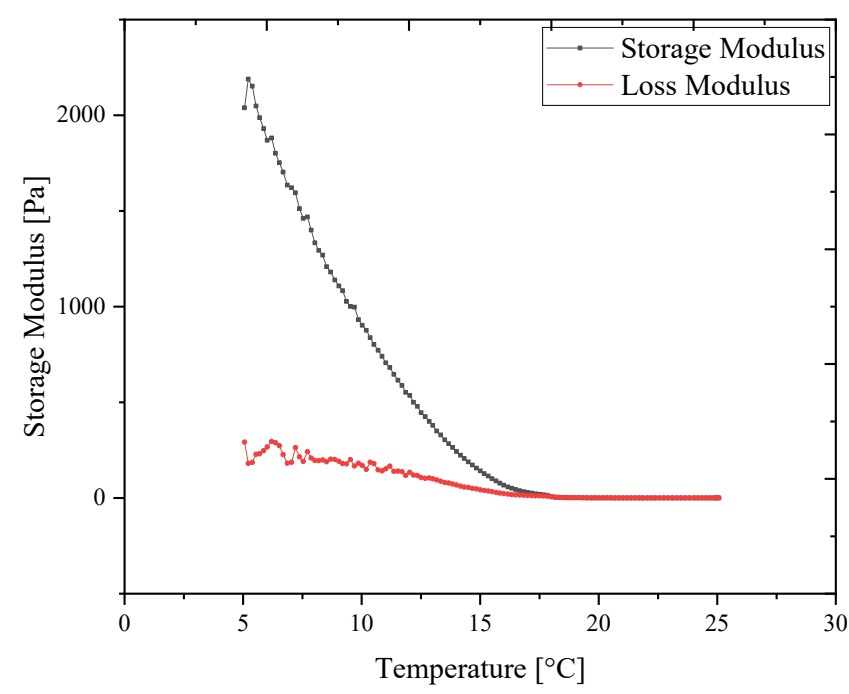

(a)

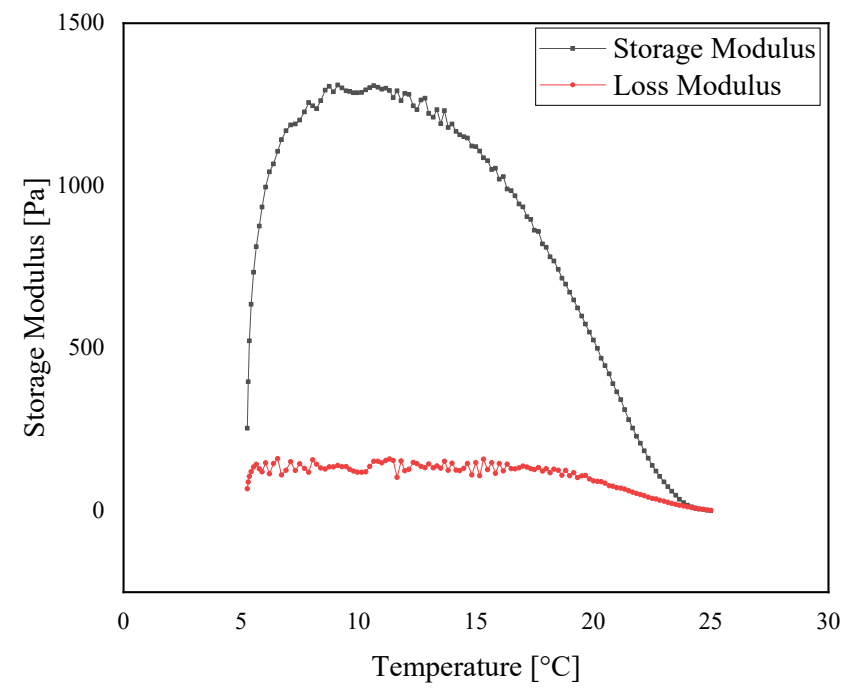

437

438

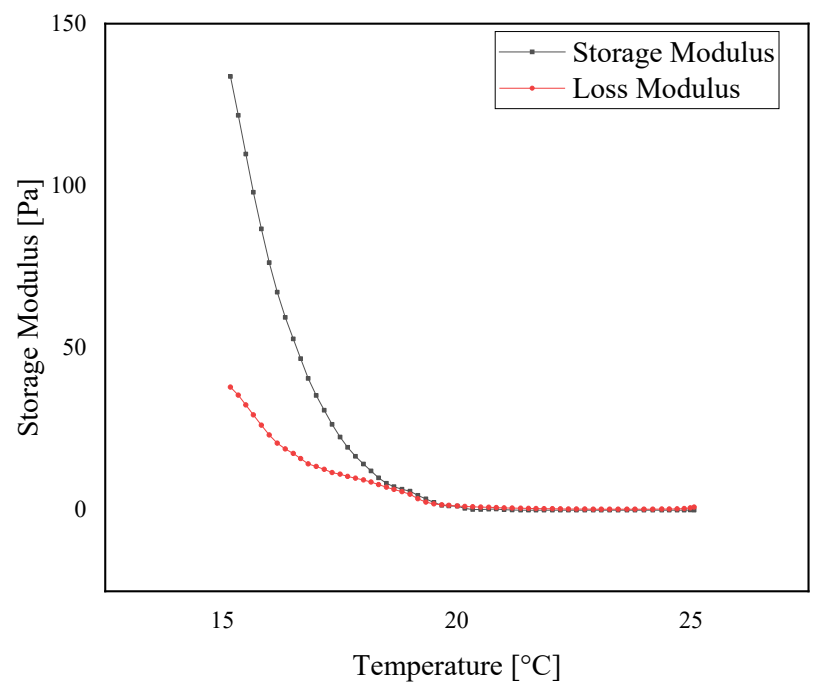

(b)

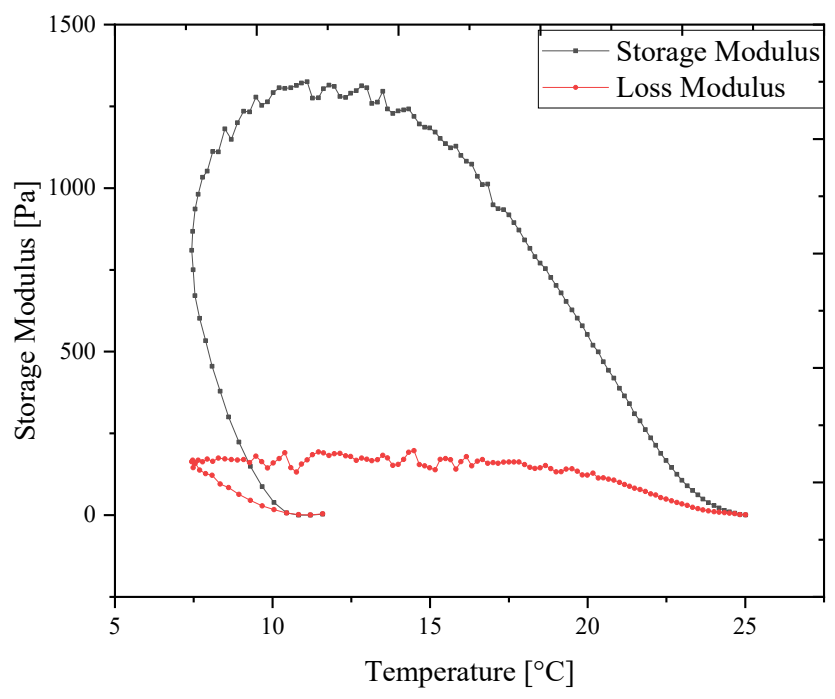

(d) 
439 Fig 8: (a) Storage modulus $\left(\mathrm{G}^{\prime}\right)$ (black symbols) and loss modulus $\left(\mathrm{G}^{\prime \prime}\right)$ (red symbols) as a

440 function of temperature during a temperature sweep at cooling for (a) Pink Perch by-products

441 gelatin, (b) bovine gelatin and followed by heating for (c) Pink Perch by-products gelatin, (d)

442 bovine gelatin (both at $1^{\circ} \mathrm{C} \min ^{-1}$ )

443 Study of storage modulus and loss modulus as a function of frequency is conducted to predict the 444 possible behavior of gelatin during storage and thereby its applicability in food products. The

445 frequency sweep test of PG and BG indicated little to no-effect of frequency on G' and G',

446 suggesting formation of a strong gel network under the test conditions (Figure 9). Similar results 447 were obtained by Boran et al., (2010) and Tan et al., (2019) with silver carp skin and tilapia skin 448 gelatin respectively.

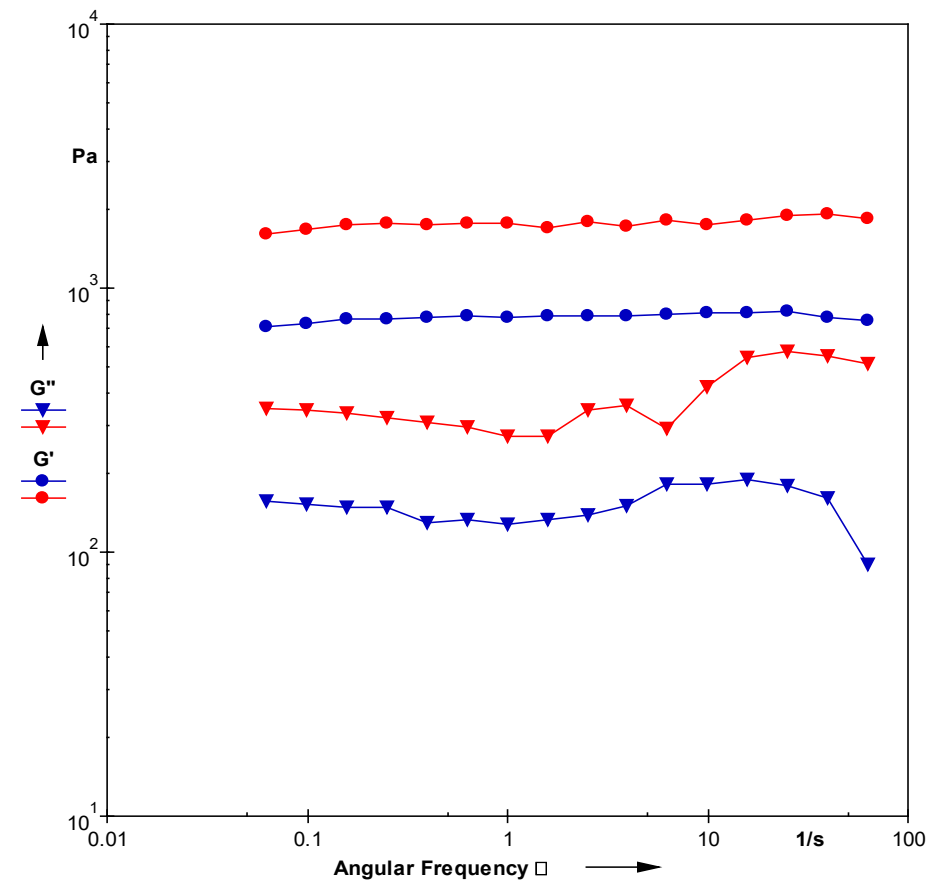

451 Fig 9: Frequency-dependent changes in storage modulus $\left(\mathrm{G}^{\prime}\right)$ (circle symbols) and loss modulus $452\left(\mathrm{G}^{\prime \prime}\right)$ (triangle symbols) at $5^{\circ} \mathrm{C}$ for Pink Perch by-products gelatin (Red) and bovine gelatin (blue)

454 Figure 10 illustrates time sweep test of $\mathrm{PG}$ and $\mathrm{BG}$ at $5^{\circ} \mathrm{C}$. Storage modulus $\left(\mathrm{G}^{\prime}\right)$ of both gelatin 455 samples was higher than its corresponding loss modulus $\left(\mathrm{G}^{\prime}\right.$ ') over the testing range indicating 
462 Fig 10: Time-dependent changes in storage modulus $\left(\mathrm{G}^{\prime}\right)$ (square symbols) and loss modulus $463\left(\mathrm{G}^{\prime \prime}\right)$ (diamond symbols) at $5^{\circ} \mathrm{C}$ for Pink Perch by-products gelatin (Red) and bovine gelatin 464 (blue)

468 469 470 471 472 micro-structure of gelatin. WHC is an important functional property responsible for determining 473 drip losses and imparting juiciness to meat product during cooking/thawing. 
474 Fat Binding Capacity (FBC) of gelatin can be attributed to presence of hydrophobic amino acids 475 and extent of non-covalent bonds influencing protein-lipid interactions. FBC of PG

$476(347.01 \pm 4.02 \%)$ was observed to be significantly higher than BG $(177.06 \pm 1.86 \%)(p<0.05)$

477 (Figure 11).

478 These interfacial traits of gelatin influence textural properties of food by interacting with water, 479 oil along with other components and hence determining applicability of gelatin in food products.

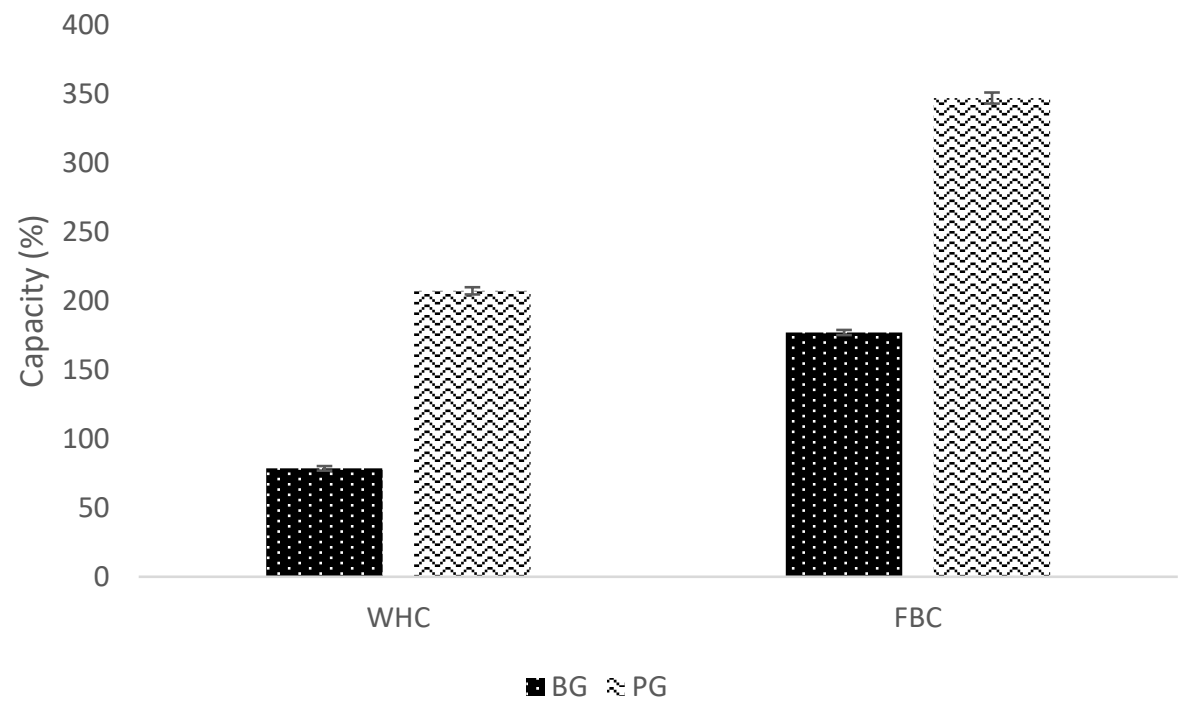

481 Fig. 11. Percentage of Water holding capacity (WHC) and percentage fat binding capacity (FBC) 482 of bovine gelatin (BG) and Pink Perch by-products gelatin (PG). Values presented as average of 483 three measurements with SD.

\subsection{Foaming capacity and foaming stability}

485 In the present study foaming capacity and foaming stability of PG and BG was examined over 486 different concentration. Foaming capacity was observed to be in range of $8.89 \%-15.6 \%$ for PG 487 and $7.78 \%-17.78 \%$ for BG. Foaming stability was found to be in the range of $7.22 \%-12.78 \%$,

$488 \quad 6.67 \%-13.89 \%$ for PG and BG (Figure 12). Results also suggested foaming capacity and foaming 489 stability of both the samples increased with increased in concentration of gelatin. Similar results 490 were observed by Dara et al., (2020) where foaming capacity and foaming stability of tuna skin 491 gelatin depicted a direct relationship with gelatin concentration. Foam formation is a result of 492 unfolding and rearrangement of smaller molecular weight peptide chain at air-liquid interface. 493 Hydrophobicity of peptide and foaming capacity are reported to have a positive correlation 
494 (Tkaczewska et al., 2018). Weak foaming properties of gelatin can also be due to degradation 495 due to extraction process leading to generation of higher amount of low molecular weight 496 peptide. These low molecular weight peptide lack in the ability of fostering film at air-water 497 interface (Jin et al., 2019).
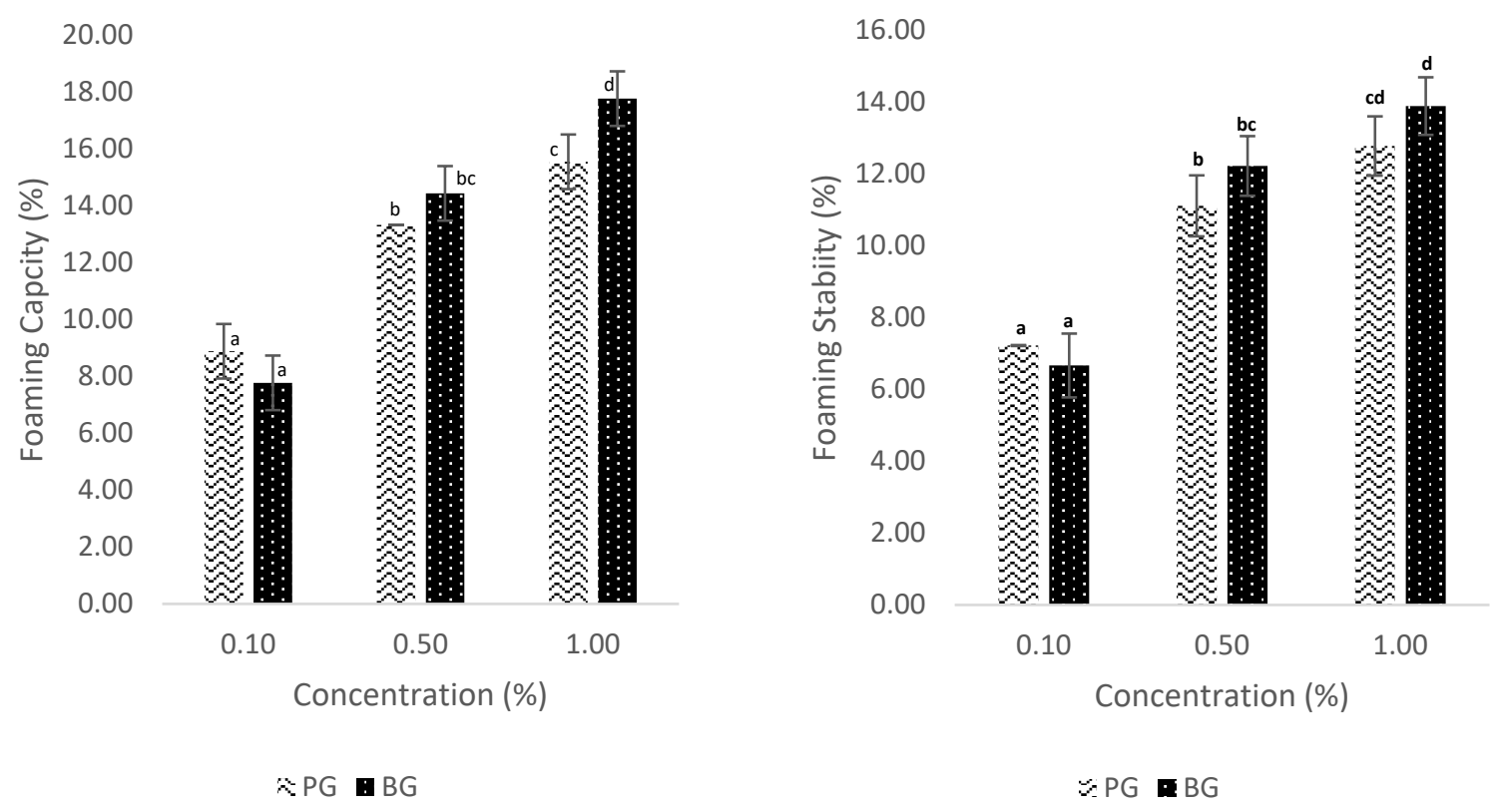

498

499

(a)

(b)

500 Fig. 12. Percentage of (a) foaming capacity and (b) foam stability of Pink Perch by-products 501 gelatin (PG) and bovine gelatin (BG). Values presented as average of three measurements with 502 SD.

\subsection{Emulsion Activity Index and Emulsion Stability Index}

504 Emulsion systems are generated by adsorption of peptides on the surface of oil droplet during 505 homogenization, followed by formation of protective layer to prevent coalescing of the oil 506 droplet (Duan et al., 2018). Effect of gelatin concentration on Emulsion Activity Index (EAI) and 507 Emulsion Stability Index (ESI) was examined in this study. The EAI values of PG diminished 508 with increase in gelatin concentration. However, a positive correlation was observed between 509 ESI and gelatin concentration. Similar patterns of EAI and ESI were observed with BG with 510 variation gelatin concentration. The PG showed highest EAI $\left(13.2 \pm 0.09 \mathrm{~m}^{2} \mathrm{~g}^{-1}\right)$ at $0.1 \%(\mathrm{w} / \mathrm{v})$ of 511 gelatin concentration and highest ESI (10.0 $\pm 0.0 \mathrm{Min})$ at 1\% (w/v) of gelatin concentration. These 
512 values were considerably lower than that of BG which depicted highest EAI of $38.4 \pm 0.25 \mathrm{~m}^{2} \mathrm{~g}^{-1}$ 513 and ESI of 8.61 \pm 0.04 Min (Figure 13). Emulsion properties of gelatin can be attributed to its

514 amphoteric nature (Koli et al., 2012). Emulsion properties of a gelatin majorly is determined by 515 gelatin composition, intrinsic properties, and conformation of gelatin (Dara et al., 2020).

516 Decrease in EAI at higher gelatin concentration can be due to higher interaction of gelatin with 517 each other due to higher hydrophilicity rendering lesser gelatin molecules for distribution at air518 water interface (Jin et al., 2019). Amount of higher molecular weight peptide and content of 519 hydrophobic amino acid residues positively influence emulsion stability. Also, higher extent of 520 intact $\alpha$ and $\beta$ peptide chain residue results in greater interaction with oil in system leading to 521 improved stability of emulsion (Duan et al., 2018).

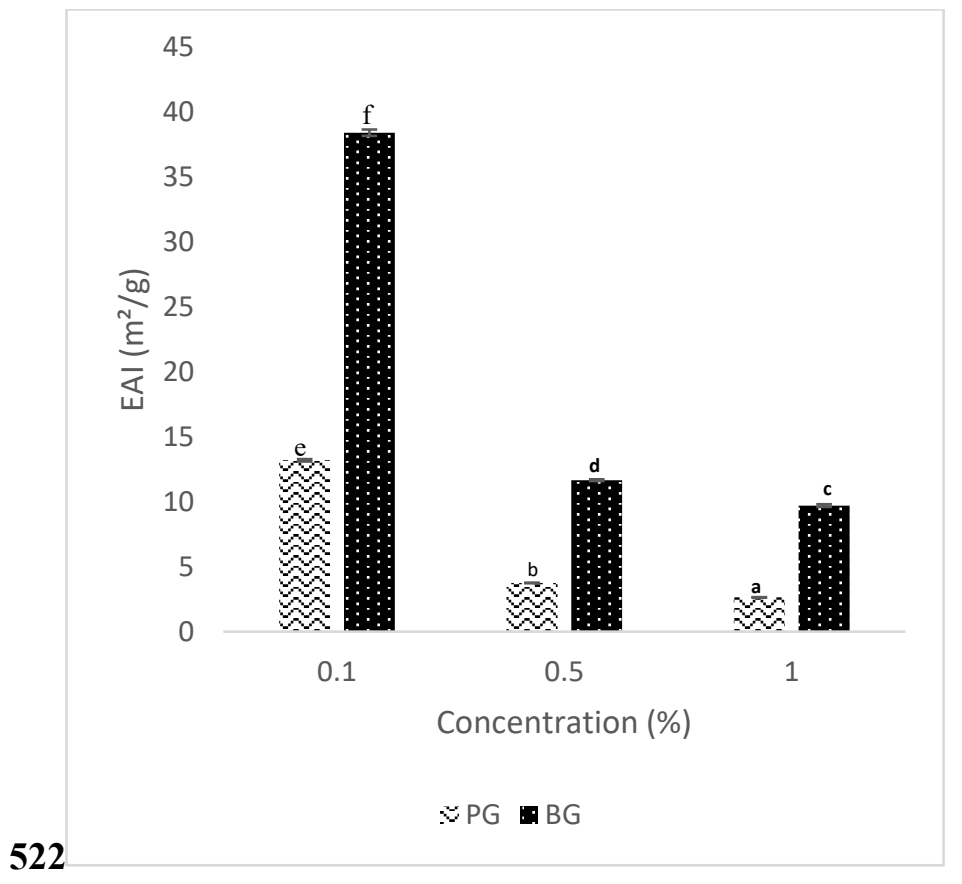

523

524 Fig. 13. (a) Emulsification activity index and (b) emulsification stability index of Pink Perch byproducts gelatin (PG) and bovine gelatin (BG). Values presented as average of three

526 measurements with SD.

528 Color is an important parameter in determining acceptability of food by aesthetically appealing 529 to consumer and acts as a quality indicator of physio-chemical changes in food. The color of PG 
530 was expressed in terms of $\mathrm{L}^{*}$ (Lightness), $\mathrm{a} *$ (redness/greenness), and $\mathrm{b}$ * (yellowness/ blueness)

531 as $86.0 \pm 0.3,0.1 \pm 0.0,8.6 \pm 0.0$ respectively as compared to $L^{*}$ value of $71.1 \pm 2$, a* value of

$5325.4 \pm 0.2$, and $b^{*}$ value of $17.7 \pm 0.3$ of BG (table 6 ). Higher $L^{*}$ and lower $a^{*}, b^{*}$ value of PG is

533 suggested proximity to white color. Whereas lower $\mathrm{L}^{*}$ value coupled with higher $\mathrm{a}^{*}$ and $\mathrm{b}^{*}$

534 value indicated darker color of BG. Darker color in gelatin can be attributed to presence of may

535 also indicate incomplete removal of mucosubstance removal during extraction process

536 (Tkaczewska et al., 2018). Lighter color of gelatin is desirable attribute as it will be easier to

537 incorporate lighter color compound in food without altering its aesthetic appeal.

538 Table 6

539 Color parameter of Pink Perch by-products gelatin (PG) and bovine gelatin (BG)

\begin{tabular}{lll}
\hline & PG & BG \\
\hline $\mathbf{L} *$ & $86.0 \pm 0.3$ & $71.1 \pm 2.1$ \\
$\mathbf{a} *$ & $0.1 \pm 0.0$ & $5.4 \pm 0.2$ \\
$\mathbf{b *}$ & $8.6 \pm 0.0$ & $17.7 \pm 0.3$ \\
$\mathbf{C *}$ & $8.6 \pm 0.0$ & $18.5 \pm 0.2$ \\
$\mathbf{h *}$ & $89.0 \pm 0.3$ & $73.2 \pm 0.8$ \\
\hline
\end{tabular}

$540 \quad$ Values are means \pm standard deviation $(n=3)$

$541 \quad 3.9 \quad$ Amino acid composition

542 Amino acid composition of $\mathrm{PG}$ and $\mathrm{BG}$ are illustrated in table 7. A higher concentration of imino

543 acids of $18.1 \%$ (proline + hydroxyproline) was observed in PG in comparison to $4.79 \%$ imino

544 acid in BG. Proline and hydroxyproline play a vital role in providing stability to triple helical

545 structure of gelatin (Karim et al., 2009) and improve visco-elastic properties subsequently

546 leading to formation of strong gel structure (Gomez-Guillen et al., 2002). Hydroxyl group

547 present in imino acid especially hydroxyproline interact with water molecules and form

548 hydrogen bond with carboxyl group. Imino acid content in fish are greatly dependent on

549 environmental temperature of fish habitat since at higher temperature greater amount of collagen

550 molecules are present to provide thermal stability to fishes. Also, charged amino acid (arginine +

551 glutamic acid + aspartic acid + lysine) constituted approximately 43.7\%. Charged amino acids

552 contribute in inter and intramolecular interaction occurring during formation of triple helix 
553 structure in gelatin. PG gelatin composed of $46.4 \%$ essential amino acids in comparison to

$55439.32 \%$ of essential amino acid content of BG.

555 Table 7:

556 Amino Acid Profile of Pink Perch by-products gelatin (PG) and bovine gelatin (BG)

\begin{tabular}{|c|c|c|}
\hline Amino Acid & PG & BG \\
\hline Taurine & nd & 1.27 \\
\hline Methionine sulfoxide & nd & 1.44 \\
\hline Hydroxyproline & 7.4 & 0.23 \\
\hline Aspartic acid + Asparagine & 0.1 & 7.37 \\
\hline Threonine & nd & 4.54 \\
\hline Serine & 0.2 & 6.32 \\
\hline Glutamic acid + Glutamine & 0.9 & 12.70 \\
\hline Proline & 10.7 & 4.54 \\
\hline Lysine & 12.7 & 6.57 \\
\hline Alanine & 10.0 & 10.75 \\
\hline Valine & 2.2 & 5.78 \\
\hline Methionine & 1.6 & 2.55 \\
\hline Isoleucine & 1.5 & 4.39 \\
\hline Leucine & 3.6 & 8.95 \\
\hline Tyrosine & 0.9 & 2.92 \\
\hline Phenylalanine & 2.9 & 5.80 \\
\hline Histidine & 2.0 & 1.79 \\
\hline Hydroxylysine & nd & 0.06 \\
\hline Glycine & 32.6 & 5.52 \\
\hline Ammonia & 3.1 & 2.20 \\
\hline Arginine & 10.1 & 4.19 \\
\hline SUM (AA* only) & 100.0 & 100.00 \\
\hline TEAA $* *$ & 46.40 & 39.32 \\
\hline
\end{tabular}




\subsection{FT-IR Spectra}

559 FTIR spectra has been used to monitor the specific functional groups and secondary structural

560 conformation of gelatin sample. Several peaks were observed in the region of $4000-500 \mathrm{~cm}^{-1}$

561 which majorly depicts amide A, B, I, II and III (Figure 14, table 8).

562 Both gelatin samples exhibited amide A near $3400 \mathrm{~cm}-1$ indicating N-H stretching coupled with

563 H-bonding and amide B representing vibration modes of asymmetric stretch of $=\mathrm{C}-\mathrm{H}$ and $-\mathrm{NH} 3$

564 at $2900 \mathrm{~cm}^{-1}$. Peak for Amide I was observed at $1600 \mathrm{~cm}^{-1}$ are caused by $\mathrm{C}=\mathrm{O}$ stretching coupled

565 with $\mathrm{C}-\mathrm{N}$ stretch and $\mathrm{CCN}$ deformation. For amide II, two peaks were observed at $1550 \mathrm{~cm}^{-1}$

566 and $1400 \mathrm{~cm}^{-1}$, which were attributed to a combination of N-H deformation vibration and the C-

567 N stretching vibration. Another peak of Amide III was observed at 1200-1100 $\mathrm{cm}^{-1}$ which was

568 corresponding to vibrations from $\mathrm{CH}_{2}$ group glycine backbone and proline sidechain. Presence of

569 amide III peak depicted disorganized gelatin structure. This phenomenon is associated with

570 interruption in interchain reactions caused by extraction parameters leading to loss of triple helix

571 structure. The peaks at amide I, II and III are commonly associated with the secondary protein

572 structure present in the skin gelatin (Sockalingam et al., 2016). The wavenumber and amplitude

573 of the major peaks in amide regions were found to be similar, implying that the secondary

574 structure and functional groups of PG and BG are similar.

575 Table 8:

576 FTIR peak locations for Pink Perch by-products gelatin (PG) and bovine gelatin (BG)

\begin{tabular}{lll}
\hline Region & PG & BG \\
\hline Amide A & 3418 & 3425 \\
Amide B & 2925 & 2919 \\
Amide I & 1640 & 1638 \\
Amide II & 1558,1415 & 1561,1415 \\
Amide III & 1236 & 1102 \\
\hline
\end{tabular}




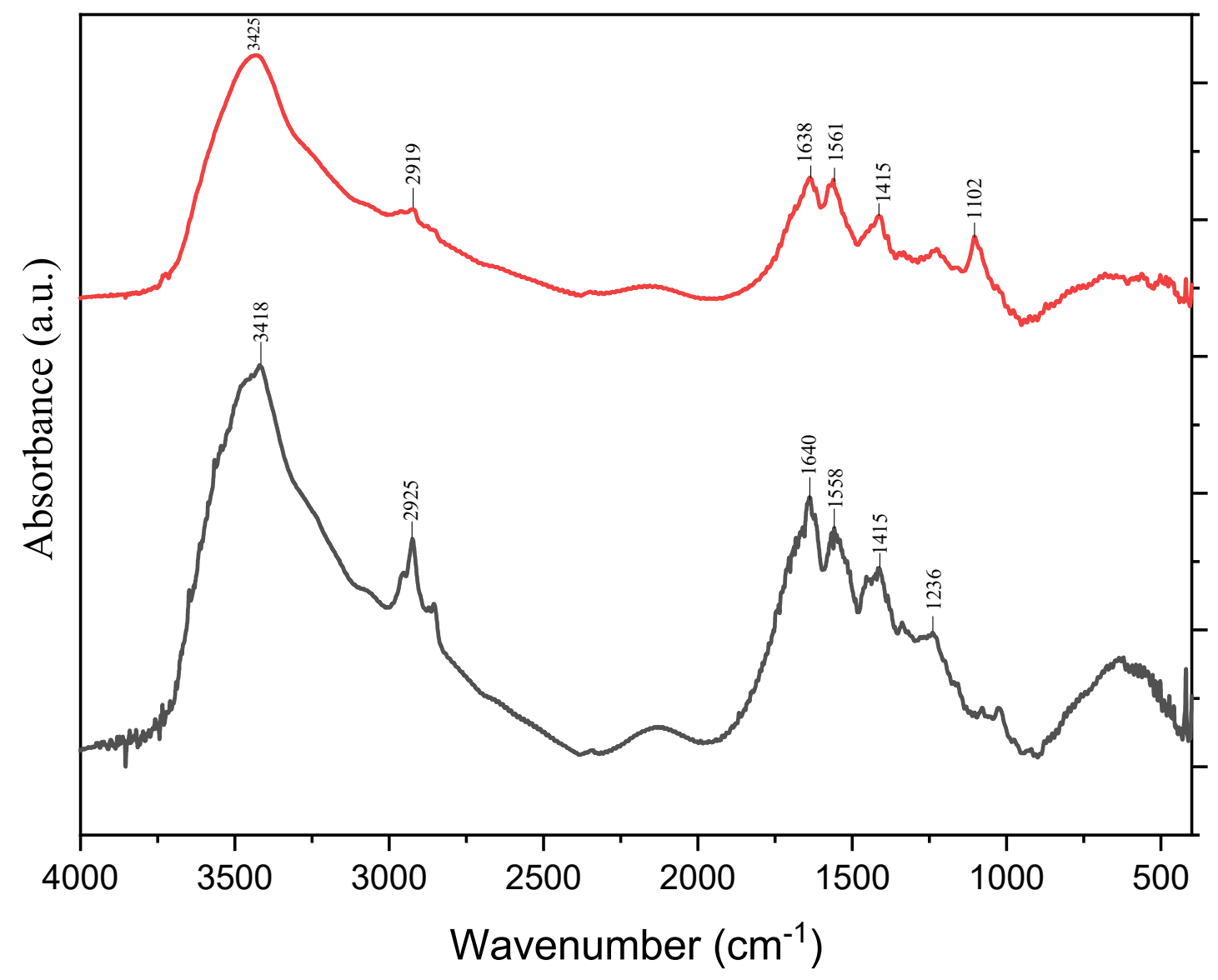

578 Fig 14: FTIR Spectra of Pink Perch by-products gelatin (PG)(Red) and Bovine gelatin (BG)

579 (Black)

\section{$580 \quad 3.11$ SEM Analysis}

581 The microstructures of PG and BG are illustrated in Fig. 15. PG has spherical and dense

582 structure. Whereas BG showed thinner strands, such a gel network had the less resistance to the

583 force applied, leading to a lower gel strength. In general, the conformation and association of

584 protein molecules in gel matrices directly contribute to gel strength of gelatin (Benjakul et al.,

585 2009). The thinner strand network had less inter-connected protein chains than the denser

586 counterpart, resulting in weaker gel strength. 


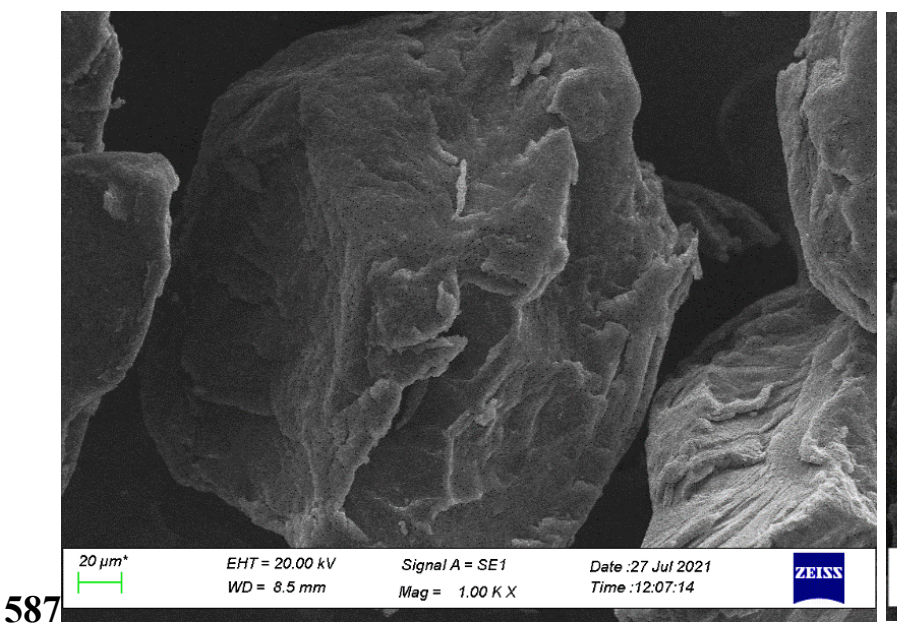

588

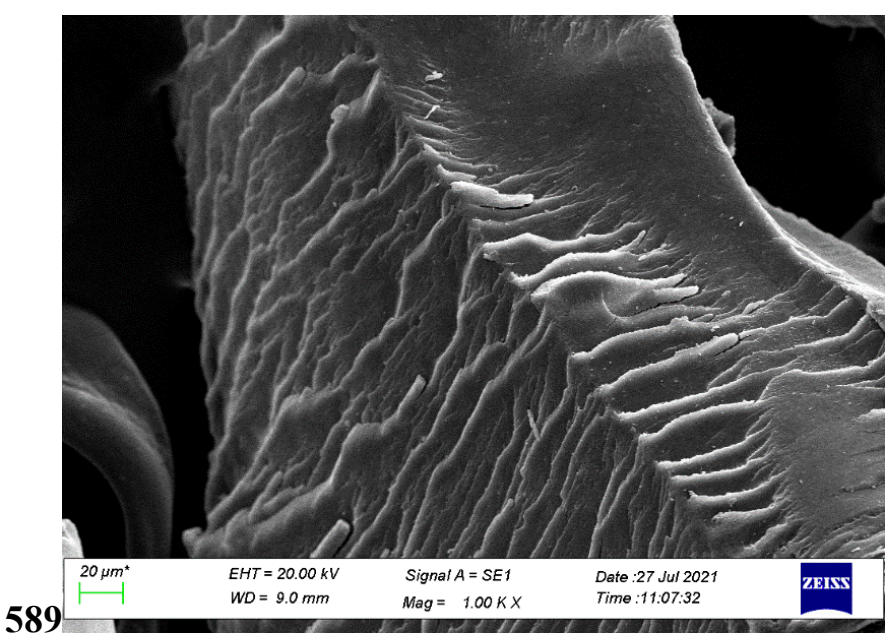

590

(c)

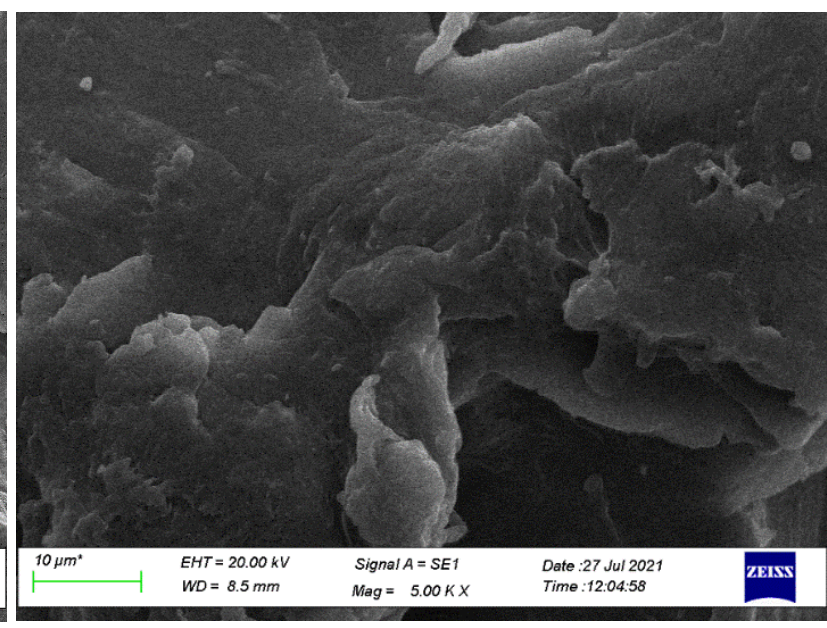

(b)

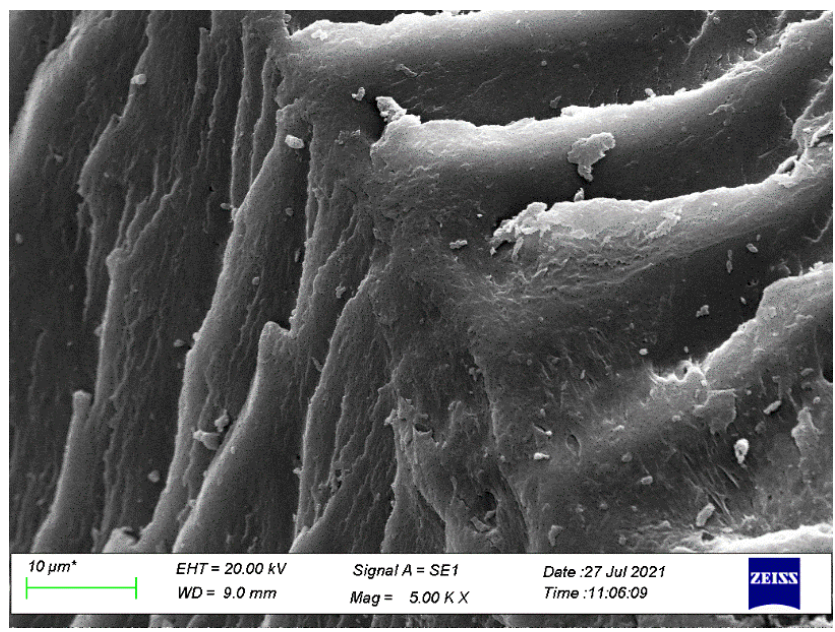

(d)

591 Fig 15: Microstructures of 6.67\% gelatin gels from Pink Perch by-products gelatin (a, b) and

592 bovine gelatin (c, d) at $1000 \times$ and $3000 \times$ magnification respectively.

\section{Conclusion}

594 In this study, gelatin extraction from industrial by-products of Pink Perch was conducted using

595 single step extraction method with acetic acid. This process was optimized using Response

596 Surface Methodology at different $\mathrm{pH}$, temperature, and time to maximize yield and L-

597 hydroxyproline content. The yield of gelatin obtained at optimized condition was $16.2 \%$ with

598 high gel strength of 793g. Moisture and ash content in the gelatin obtained at optimized

599 condition was within the FSSAI standards of edible gelatin. Use of organic acid makes optimized 
600 method cost effective and environmentally sustainable. Further, Pink Perch by-products gelatin

601 obtained by this method exhibited fine emulsifying activity, foam expansion, water- and oil

$\mathbf{6 0 2}$ absorption capacity suggesting its potential application for development of various food systems.

603 The physicochemical and rheological properties of the Pink Perch by-products gelatin were

604 comparable to the control bovine gelatin. Thus, providing a sustainable alternative of mammalian

605 gelatin along with added benefits of reduced risk of pathogenic vectors such as prions and

606 greater acceptability from Kosher and Halal consumers.

6075 Conflict of Interest

608 The authors confirm that they have no conflicts of interest with respect to the work described in 609 this manuscript.

6106 Acknowledgement

611 NK and Khushboo would like to acknowledge the help extended by Dr. Shalini Rudra, Principal

612 Scientist, IARI, for analysis of gelatin. Authors are also indebted to Department of

613 Biotechnology, Government of India for providing the grant no. BT/IN/INNO-

614 INDIGO/12/NK/2017-18 \& 21/2/2018 to Dr. Nutan Kaushik for conducting the research.

6157 Contribution of Author's

$616 \mathrm{NK}$ and Khushboo designed the experiment. Khushboo conducted the experiment and wrote the

617 manuscript. Dr. NK, Dr. RS, Dr. KW and AK reviewed the manuscript.

6188 Data Availability

619 The datasets generated during and/or analysed during the current study is present in manuscript 620 and has no further associated data.

\section{References}

622 Abdelhedi, O., Nasri, R., Mora, L., Toldrá, F., Nasri, M., \& Jridi, M. (2017). Collagenous

623 proteins from black-barred halfbeak skin as a source of gelatin and bioactive peptides. Food

624 Hydrocolloids, 70, 123-133. 
625 Benjakul, S., Oungbho, K., Visessanguan, W., Thiansilakul, Y., \& Roytrakul, S. (2009).

626 Characteristics of gelatin from the skins of bigeye snapper, Priacanthus tayenus and Priacanthus 627 macracanthus. Food Chemistry, 116(2), 445-451.

628 Bergman, I., \& Loxley, R. (1963). Two improved and simplified methods for the 629 spectrophotometric determination of hydroxyproline. Analytical chemistry, 35(12), 1961-1965.

630 Boran, G., Mulvaney, S. J., \& Regenstein, J. M. (2010). Rheological properties of gelatin from 631 silver carp skin compared to commercially available gelatins from different sources. Journal of 632 food science, 75(8), E565-E571.

633 Cho, S. M., Gu, Y. S., \& Kim, S. B. (2005). Extracting optimization and physical properties of 634 yellowfin tuna (Thunnus albacares) skin gelatin compared to mammalian gelatins. Food 635 Hydrocolloids, 19(2), 221-229.

636 Dara, P. K., Raghavankutty, M., Sebastian, N., Chatterjee, N. S., Mathew, S., Ravishankar, C. 637 N., \& Anandan, R. (2020). Rheological, Physico-chemical, and Surface-Active Properties of 638 Gelatin Extracted from Bigeye Tuna (Thunnus obesus) Skin Waste. Journal of Aquatic Food 639 Product Technology, 29(5), 428-444.

640 Duan, R., Zhang, J., Liu, L., Cui, W., \& Regenstein, J. M. (2018). The functional properties and 641 application of gelatin derived from the skin of channel catfish (Ictalurus punctatus). Food 642 chemistry, 239, 464-469

643 Elavarasan, K., Kumar, A., Uchoi, D., Tejpal, C. S., Ninan, G., \& Zynudheen, A. A. (2017).

644 Extraction and characterization of gelatin from the head waste of tiger tooth croaker (Otolithes 645 ruber). Waste and biomass valorization, 8(3), 851-858.

646 FAO. 2020. The State of World Fisheries and Aquaculture 2020. Sustainability in action. Rome.

647 Gómez-Guillén, M. C., Turnay, J., Fernández-Dıa, M. D., Ulmo, N., Lizarbe, M. A., \& 648 Montero, P. (2002). Structural and physical properties of gelatin extracted from different marine 649 species: a comparative study. Food Hydrocolloids, 16(1), 25-34. 
650 Hue, C. T., Hang, N. T. M., \& Razumovskaya, R. G. (2017). Physicochemical Characterization

662

663

664 Kumar, D. P., Chandra, M. V., Elavarasan, K., \& Shamasundar, B. A. (2017). Structural

665 properties of gelatin extracted from croaker fish (Johnius sp) skin waste. International journal of of Gelatin Extracted from European Perch (Perca fluviatilis) and Volga Pikeperch (Sander volgensis) Skins. Turkish journal of fisheries and aquatic sciences, 17(6), 1117-1125.

Jin, W. G., Pei, J., Du, Y. N., Pan, J., Gao, R., Chen, D. J., \& Zhu, B. W. (2019).

Characterization and Functional Properties of Gelatin Extracted from Chinese Giant Salamander (Andrias Davidianus) Skin. Journal of Aquatic Food Product Technology, 28(8), 861-876.

Karim, A. A., \& Bhat, R. (2009). Fish gelatin: properties, challenges, and prospects as an alternative to mammalian gelatins. Food hydrocolloids, 23(3), 563-576.

Koli, J. M., Basu, S., Nayak, B. B., Patange, S. B., Pagarkar, A. U., \& Gudipati, V. (2012). Functional characteristics of gelatin extracted from skin and bone of Tiger-toothed croaker (Otolithes ruber) and Pink perch (Nemipterus japonicus). Food and bioproducts processing, 90(3), 555-562.

Krul, E. S. (2019). Calculation of nitrogen-to-protein conversion factors: A review with a focus on soy protein. Journal of the American Oil Chemists' Society, 96(4), 339-364.

666

667 Mafazah, E. M., Pranoto, Y., \& Rohman, A. (2018, March). Extracting of yellowfin tuna 668 (Thunnus albacares) fish skin gelatin as influenced by alkaline concentration and extraction 669 times. In IOP Conference Series: Earth and Environmental Science (Vol. 139, No. 1, p. 012047). 670 IOP Publishing.

671 Martins, M. E. O., Sousa, J. R., Claudino, R. L., Lino, S. C. O., Vale, D. A. D., Silva, A. L. C., \& 672 De Souza, B. W. (2018). Thermal and chemical properties of gelatin from tilapia (Oreochromis 673 niloticus) scale. Journal of Aquatic Food Product Technology, 27(10), 1120-1133.

674 Mi, H., Wang, C., Chen, J., Xu, Y., Li, X., Li, J., ... \& Lao, M. (2019). Characteristic and 675 functional properties of gelatin from the bones of alaska pollock (Theragra chalcogramma) and 676 yellowfin sole (Limanda aspera) with papain-aided process. Journal of Aquatic Food Product 677 Technology, 28(3), 287-297. 
678 Mirzapour-Kouhdasht, A., Moosavi-Nasab, M., Krishnaswamy, K., \& Khalesi, M. (2020).

679 Optimization of gelatin production from Barred mackerel by-productss: Characterization and $\mathbf{6 8 0}$ hydrolysis using native and bovine proteases. Food Hydrocolloids, 108, 105970.

681 Osnes, K. K., \& Mohr, V. (1985). On the purification and characterization of three anionic, 682 serine-type peptide hydrolases from Antarctic krill, Euphausia superba. Comparative

683 Biochemistry and Physiology Part B: Comparative Biochemistry, 82(4), 607-619.

684 Singh, R. K., \& Balange, A. K. (2005). Characteristics of pink perch (Nemipterus japonicus)

685 surimi at frozen temperature. Journal of food processing and preservation, 29(1), 75-83.

686 Sockalingam, K., Nelson, H., Idris, M. I., \& Abdullah, H. Z. (2016). Effects of pre-treatment 687 durations on properties of black tilapia (Oreochromis Mossambicus) skin gelatin. In Materials 688 Science Forum (Vol. 840, pp. 146-150). Trans Tech Publications Ltd.

689 Tan, C. C., Karim, A. A., Uthumporn, U., \& Ghazali, F. C. (2019). Effect of extraction 690 temperature on the physicochemical properties of gelatine from the skin of black tilapia 691 (Oreochromis mossambicus). Journal of Physical Science, 30, 1-21.

692 Tkaczewska, J., Morawska, M., Kulawik, P., \& Zając, M. (2018). Characterization of carp 693 (Cyprinus carpio) skin gelatin extracted using different pretreatments method. Food 694 Hydrocolloids, 81, 169-179.

695 Yang, H., Wang, Y., Jiang, M., Oh, J., Herring, J.L., \& Zhou, P. (2007). 2-step optimization of 696 the extraction and subsequent physical properties of channel catfish (Ictalurus punctatus) skin 697 gelatin. Journal of food science, 72 4, C188-95.

698 Zhang, T., Sun, R., Ding, M., Tao, L., Liu, L., Tao, N., \& Zhong, J. (2020). Effect of extraction 699 methods on the structural characteristics, functional properties, and emulsion stabilization ability 700 of Tilapia skin gelatins. Food Chemistry, 328, 127114. 